\title{
Libres de espacio libre / en la cuerda floja
}

\section{Free of free space / on the tightrope}

\section{Edurne González Ibáñez}

Universidad del País Vasco

edurne.gonzalez@ehu.eus
Recibido 10/12/2020 Revisado 11/01/2021

Aceptado 11/01/2021 Publicado 30/04/2021

\section{Resumen:}

A partir del proyecto "Libres de espacio libre / en la cuerda floja" realizado a finales de 2019 y principios de 2020, he desarrollado un proceso creativo y de investigación artística de código abierto basado en la experimentación audiovisual y fotográfica, con el objetivo de generar espacios de fricción visual y conexiones conceptuales a partir del desplazamiento de algunas posibilidades que ofrecen las tecnologías de observación de(sde) la tierra, conocida como industria newspace, en la que numerosos países están invirtiendo exponencialmente. Convertidos en imagen, como diría Hito Steyerl, muy poco podemos hacer para dejar de ser vistos. [espacio libre], [post-futuro] y [colapso] son los inputs conceptuales y operativos que articulados en estructuras híbridas nos permiten establecer extrañas relaciones de parentesco que nos conducen a repensar algunas ideas desde las herramientas teóricas que proporciona el Chthuluceno de Donna J. Haraway.

(El proyecto ha sido realizado gracias a una subvención del Gobierno Vasco en el área de artes plásticas y visuales de la convocatoria 2019).

Sugerencias para citar este artículo,

González Ibáñez, Edurne (2021). Libres de espacio libre / en la cuerda floja. Tercio Creciente (Monográfico extraordinario V), (pp. 61-106), https://dx.doi.org/10.17561/rtc.extra5.5799

GONZÁLEZ IBÁÑEZ, EDURNE. Libres de espacio libre / en la cuerda floja. Tercio Creciente (Monográfico extraordinario V) abril 2021, pp. 61-106, https://dx.doi.org/10.17561/rtc.extra5.5799 


\section{Abstract:}

From the project "Free of free space / on the tightrope" performed at the end of 2019 and early 2020, I have developed a creative and open-source artistic research process based on audiovisual and photographic experimentation, with the objective of generating visual friction spaces and conceptual connections from the displacement of some possibilities offered by the earth's observation technologies, known as the newspace industry, in which many countries are investing exponentially. Converted into image, as Hito Steyerl would say, we can do very little to stop being seen. [free space], [post-future] and [collapse] are the conceptual and operational inputs that articulated in hybrid structures allow us to establish strange kinship relations that lead us to rethink some ideas from the theoretical tools provided by the Chthuluceno of Donna J. Haraway.

(The project has been performed thanks to a grant from the Basque Government in the area of plastic and visual arts from the 2019 call).

\section{Palabras Clave:}

\#tecnologíasdelaimagen; \#observaciondelatierra; \#imagendato; \#paisajehumano

Key words:

\#imagetechnology; \#earthobservation; \#imagedata; \#humanlandscape

Sugerencias para citar este artículo,

González Ibáñez, Edurne (2021). Libres de espacio libre / en la cuerda floja. Tercio Creciente (Monográfico extraordinario V), (pp. 61-106), https://dx.doi.org/10.17561/rtc.extra5.5799

GONZÁLEZ IBÁÑEZ, EDURNE. Libres de espacio libre / en la cuerda floja. Tercio Creciente (Monográfico extraordinario V) abril 2021, pp. 61-106, https://dx.doi.org/10.17561/rtc.extra5.5799 


\section{Tercio Creciente}

ISSN: $2340-9096$

https://doi.org/10.17561/rtc.extra5.5799

ख) $\alpha$
Revista de Estudios en Sociedad,

Artes y Gestión Cultural
Monográfico

Extraordinario V

Abril 2021

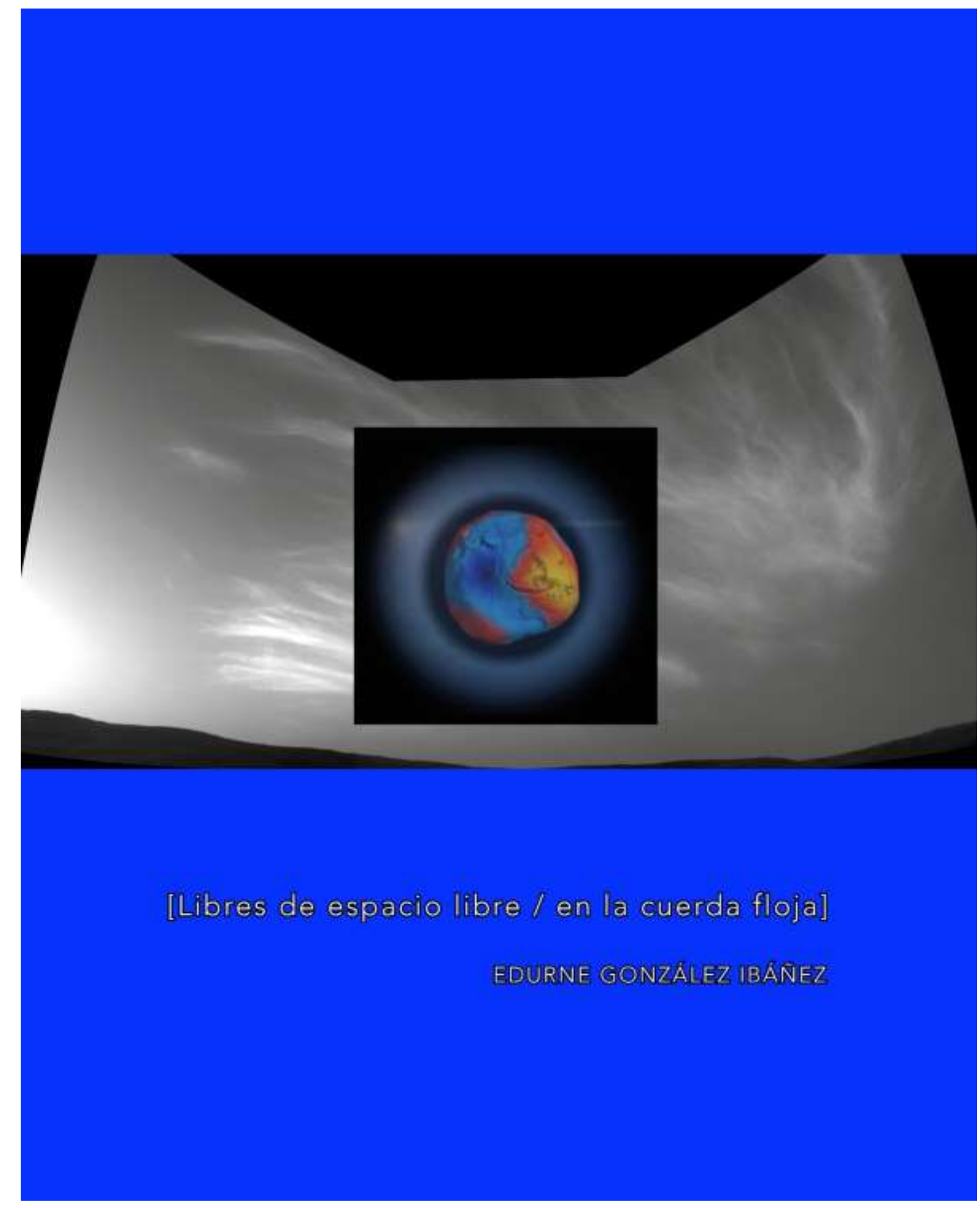




\section{Tercio Creciente}

ISSN: $2340-9096$

https://doi.org/10.17561/rtc.extra5.5799

a)
Revista de Estudios en Sociedad,

Artes y Gestión Cultural

Extraordinario V

Abril 2021

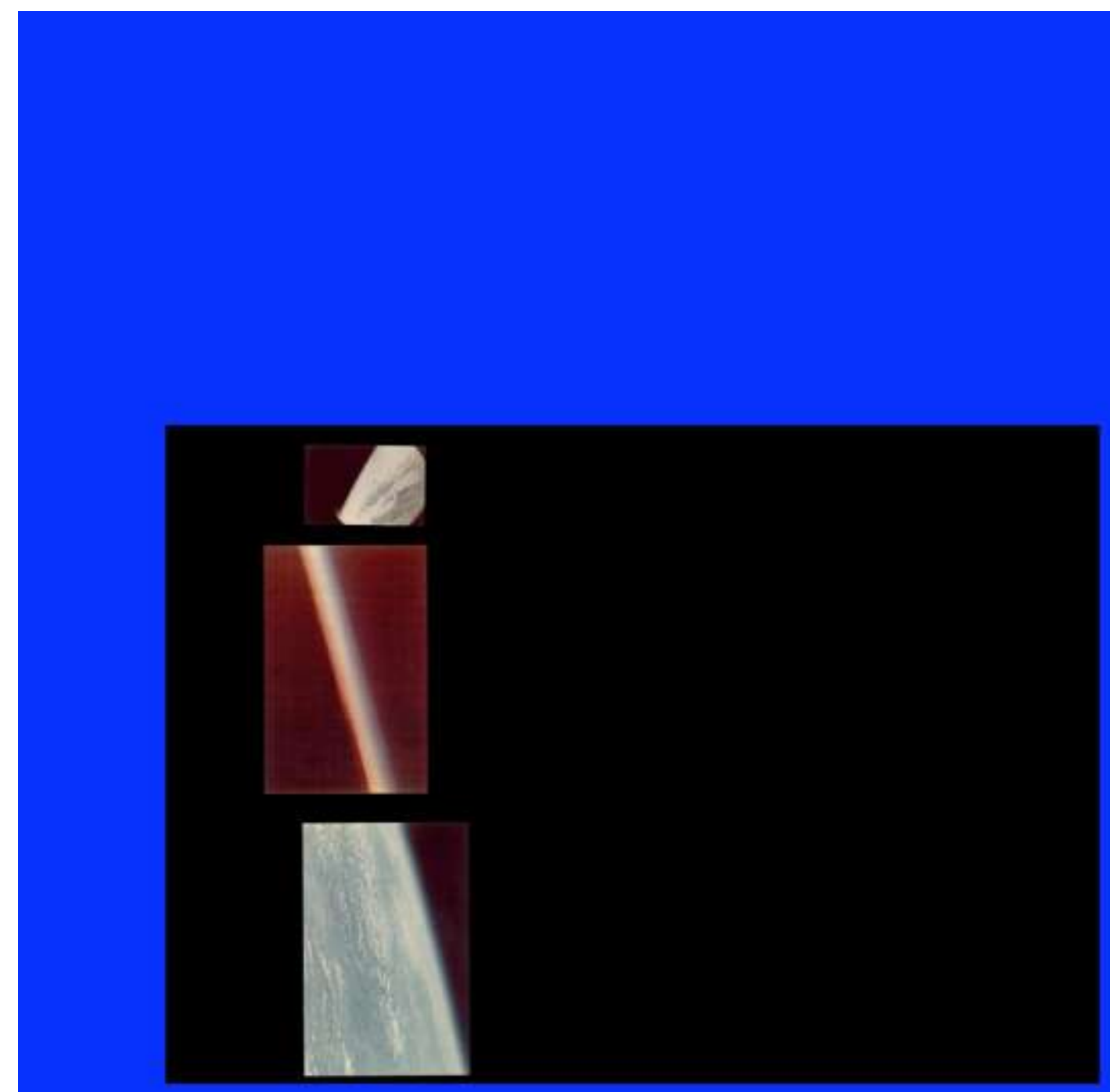


ISSN: $2340-9096$

Sistemas de observación y captura puestos en órbita, constelaciones satelitales, ondas y señales electromagnéticas en movimiento, conexiones inalámbricas, antenas isotrópicas, flujo de imágenes inmateriales convertidas en datos, almacenes digitales, procesos y operaciones algorítmicas, secuencias de descarga, memorias fábrica convertidas en destellos lumínicos discontinuos, sobreexposición incontrolable, retroalimentación vacía, ruido de fondo, interferencia acelerada, mala señal, conexión interrumpida, reseteo programado... 
ISSN: $2340-9096$

https://doi.org/10.17561/rtc.extra5.5799 (x) $\alpha$
Revista de Estudios en Sociedad,

Artes y Gestión Cultural
Monográfico

Extraordinario V

Abril 2021

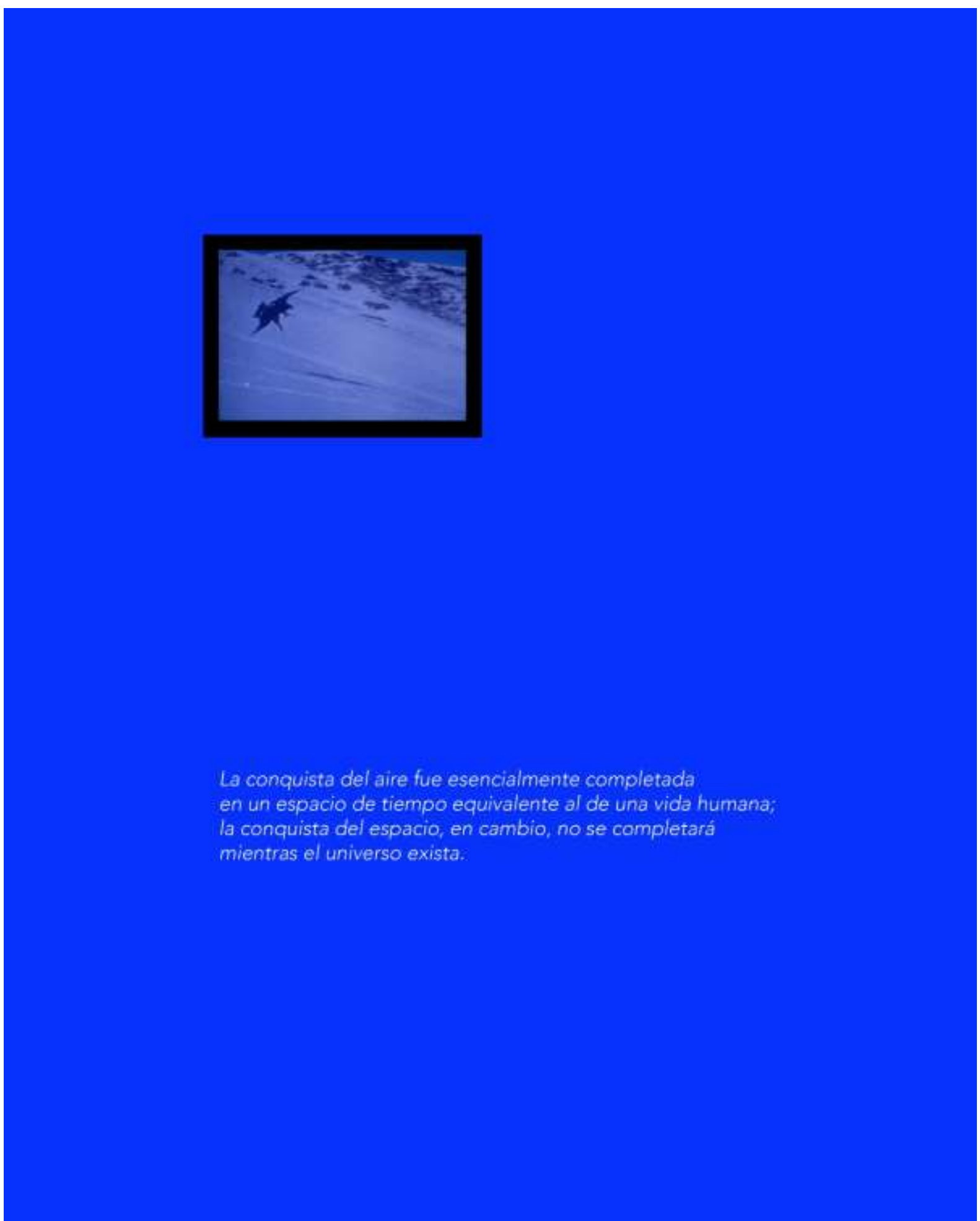

https://revistaselectronicas.ujaen.es/index.php/RTC 
ISSN: 2340-9096

https://doi.org/10.17561/rtc.extra5.5799 ख 0
Abril 2021

[espacio libre] 


\section{Tercio Creciente}

ISSN: 2340-9096

https://doi.org/10.17561/rtc.extra5.5799

ख 0
Revista de Estudios en Sociedad, Artes y Gestión Cultural
Monográfico

Extraordinario V

Abril 2021

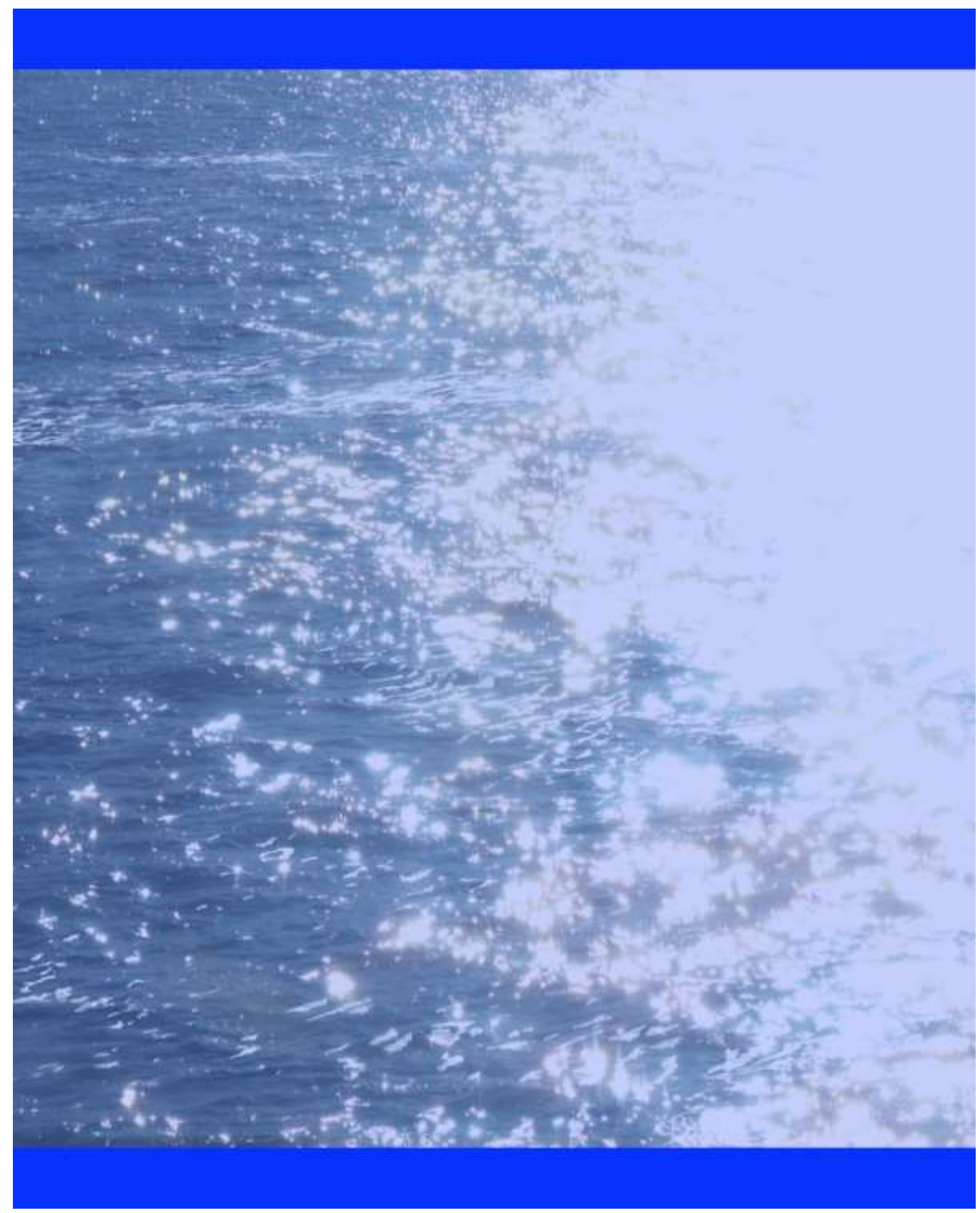




\section{Tercio Creciente}

ISSN: $2340-9096$

https://doi.org/10.17561/rtc.extra5.5799

(2)
Revista de Estudios en Sociedad, Artes y Gestión Cultural
Monográfico

Extraordinario V

Abril 2021

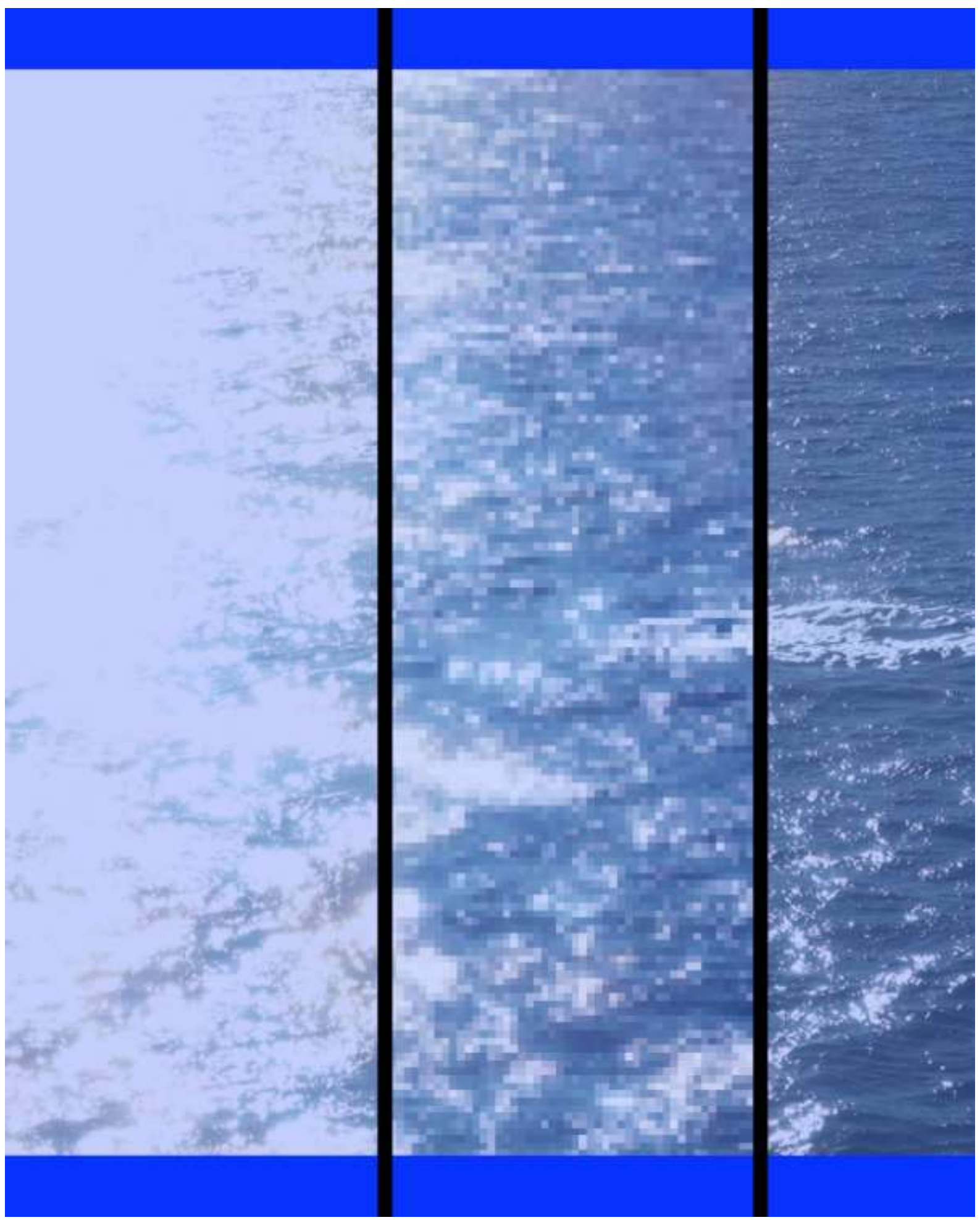


Revista de Estudios en Sociedad,

Artes y Gestión Cultural

ISSN: 2340-9096

https://doi.org/10.17561/rtc.extra5.5799

ख 0
Monográfico

Extraordinario V

Abril 2021

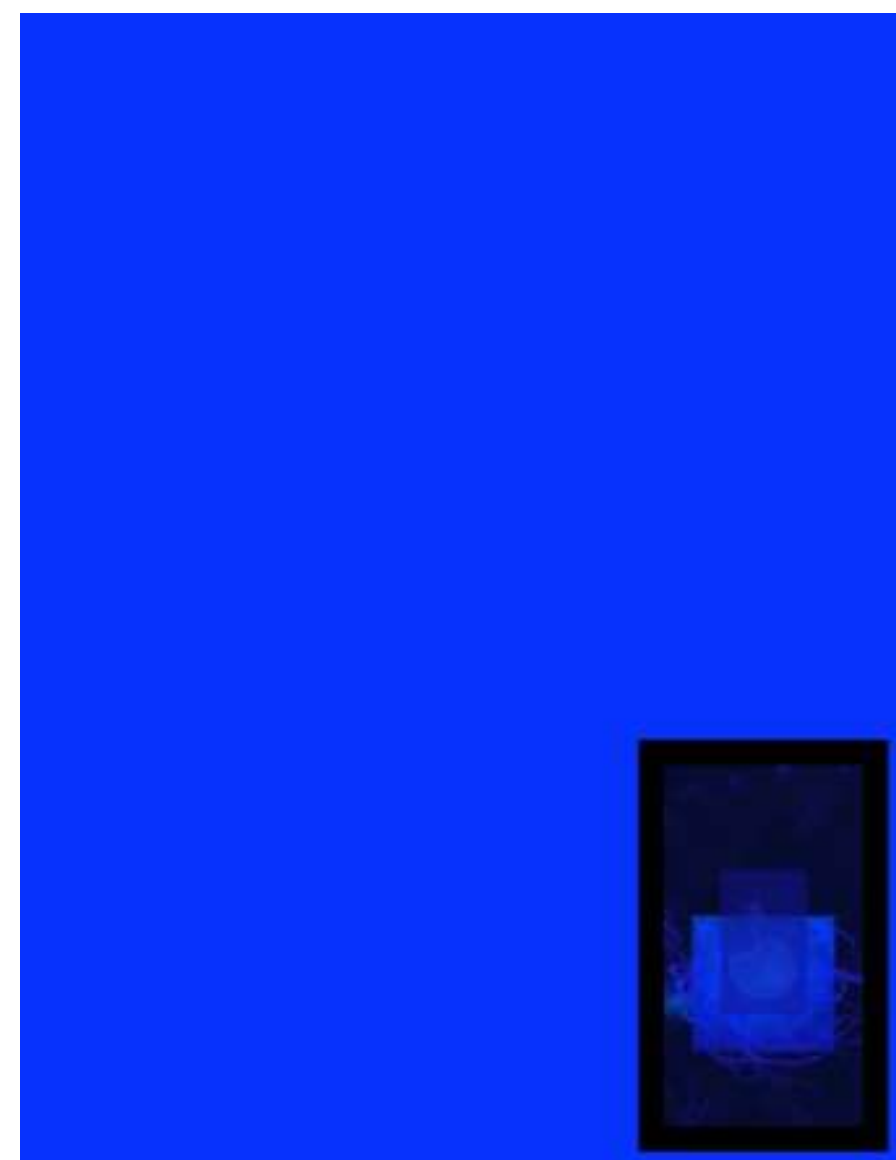


ISSN: $2340-9096$

https://doi.org/10.17561/rtc.extra5.5799

(x) 0
Revista de Estudios en Sociedad,

Artes y Gestión Cultural

Extraordinario V

Abril 2021

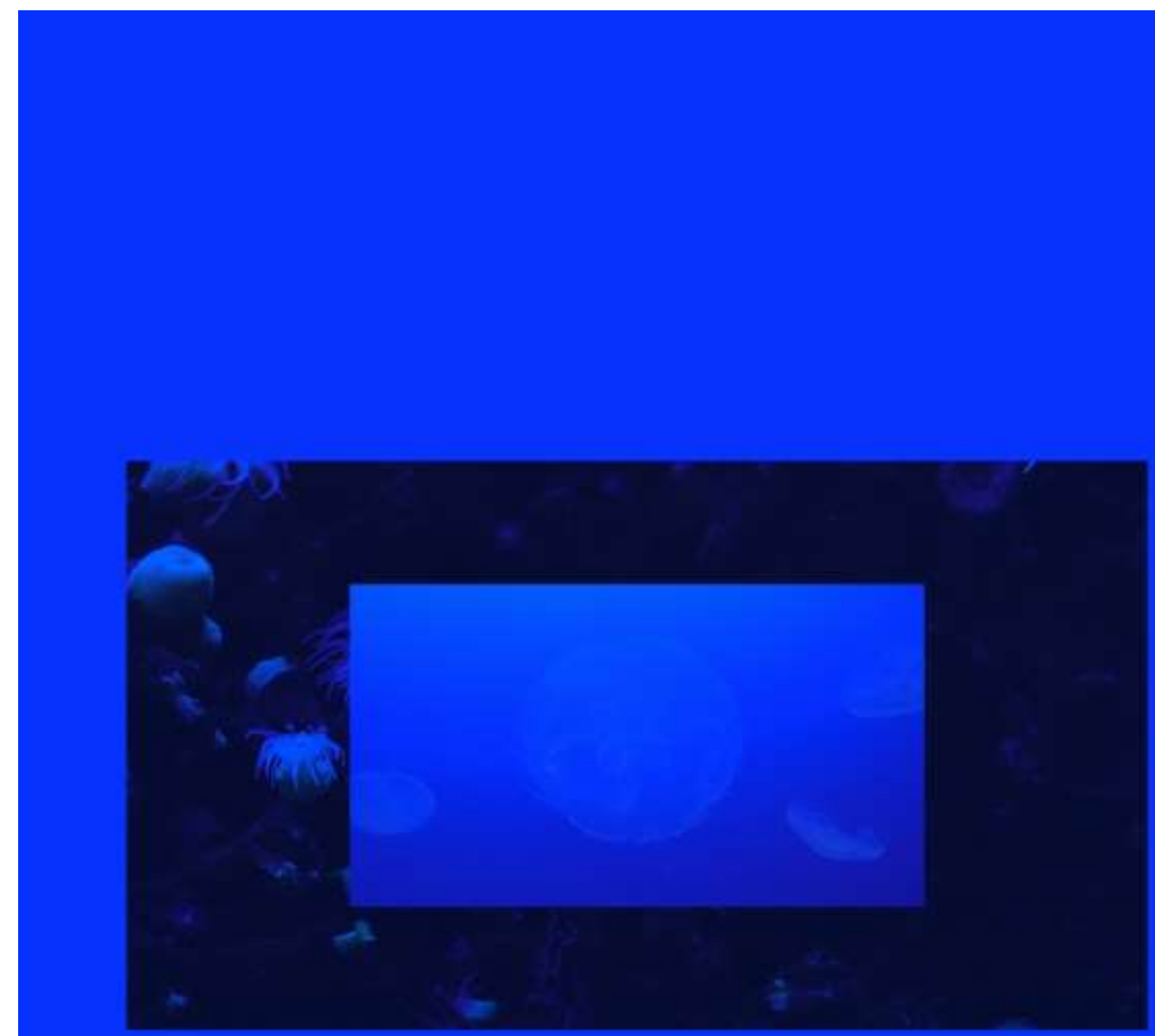




\section{Tercio Creciente}

ISSN: $2340-9096$

https://doi.org/10.17561/rtc.extra5.5799

(x) $\alpha$
Revista de Estudios en Sociedad,

Artes y Gestión Cultural

Monográfico

Extraordinario V

Abril 2021

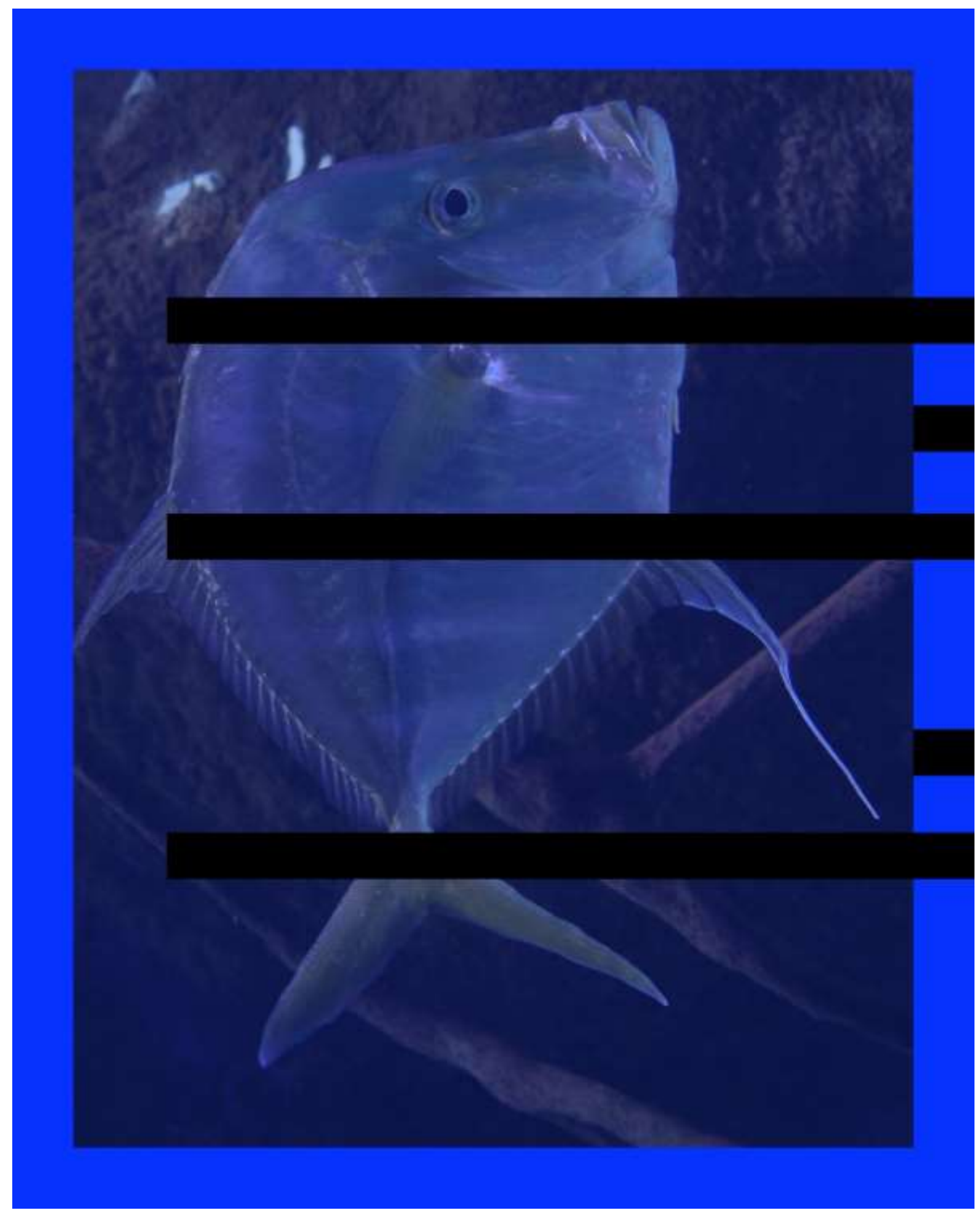




\section{Tercio Creciente}

ISSN: $2340-9096$

https://doi.org/10.17561/rtc.extra5.5799

(x)
Revista de Estudios en Sociedad,

Artes y Gestión Cultural
Monográfico

Extraordinario V

Abril 2021

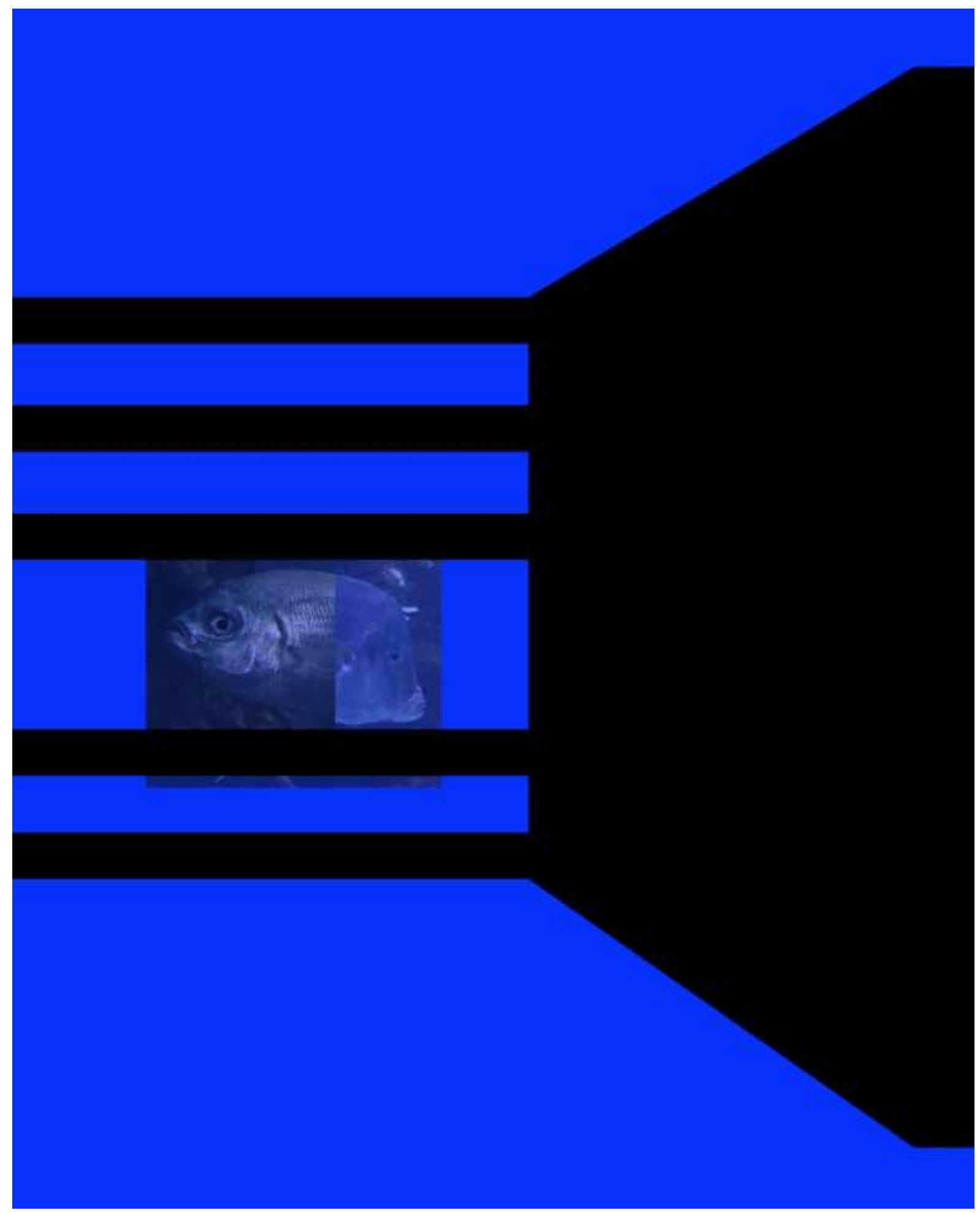


ISSN: $2340-9096$

https://doi.org/10.17561/rtc.extra5.5799 (x)
Revista de Estudios en Sociedad, Artes y Gestión Cultural

Extraordinario V

Abril 2021

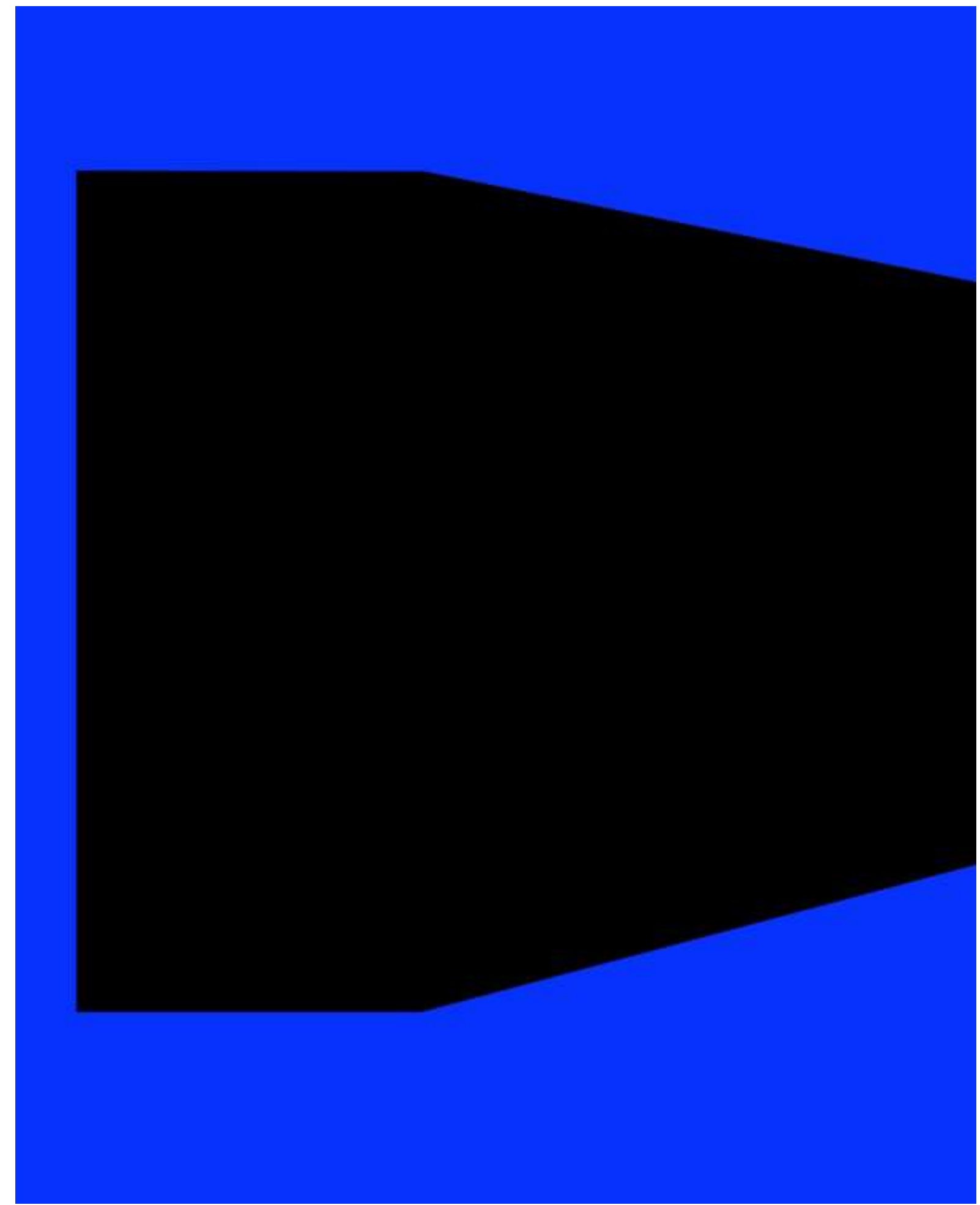




\section{Tercio Creciente}

ISSN: $2340-9096$

https://doi.org/10.17561/rtc.extra5.5799

(x)
Revista de Estudios en Sociedad, Artes y Gestión Cultural
Monográfico

Extraordinario V

Abril 2021

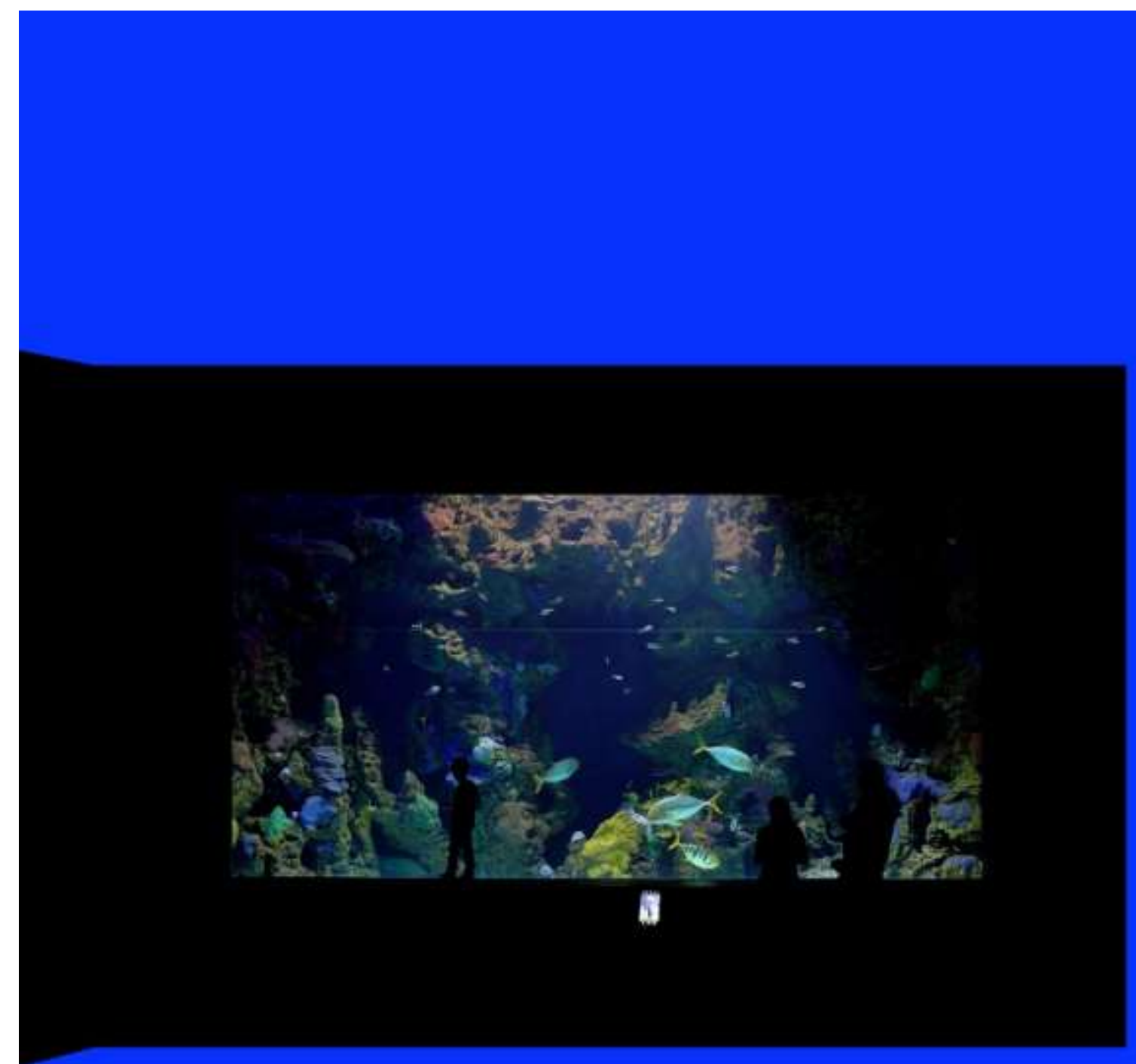




\section{Tercio Creciente}

ISSN: 2340-9096

https://doi.org/10.17561/rtc.extra5.5799

(x)
Revista de Estudios en Sociedad,

Artes y Gestión Cultural
Monográfico

Extraordinario V

Abril 2021

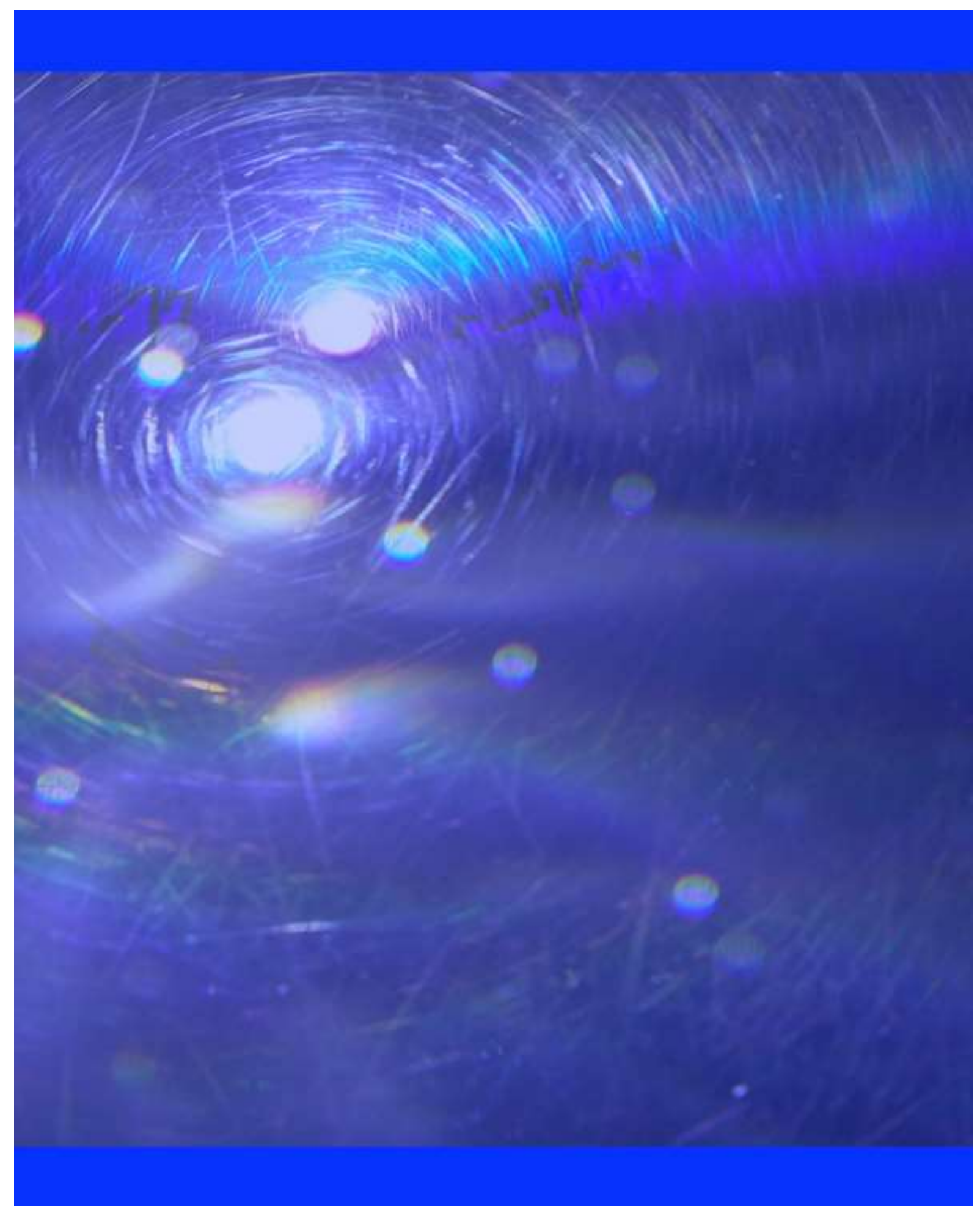


Revista de Estudios en Sociedad,

Artes y Gestión Cultural

ISSN: 2340-9096

https://doi.org/10.17561/rtc.extra5.5799

ख 0
Extraordinario V

Abril 2021

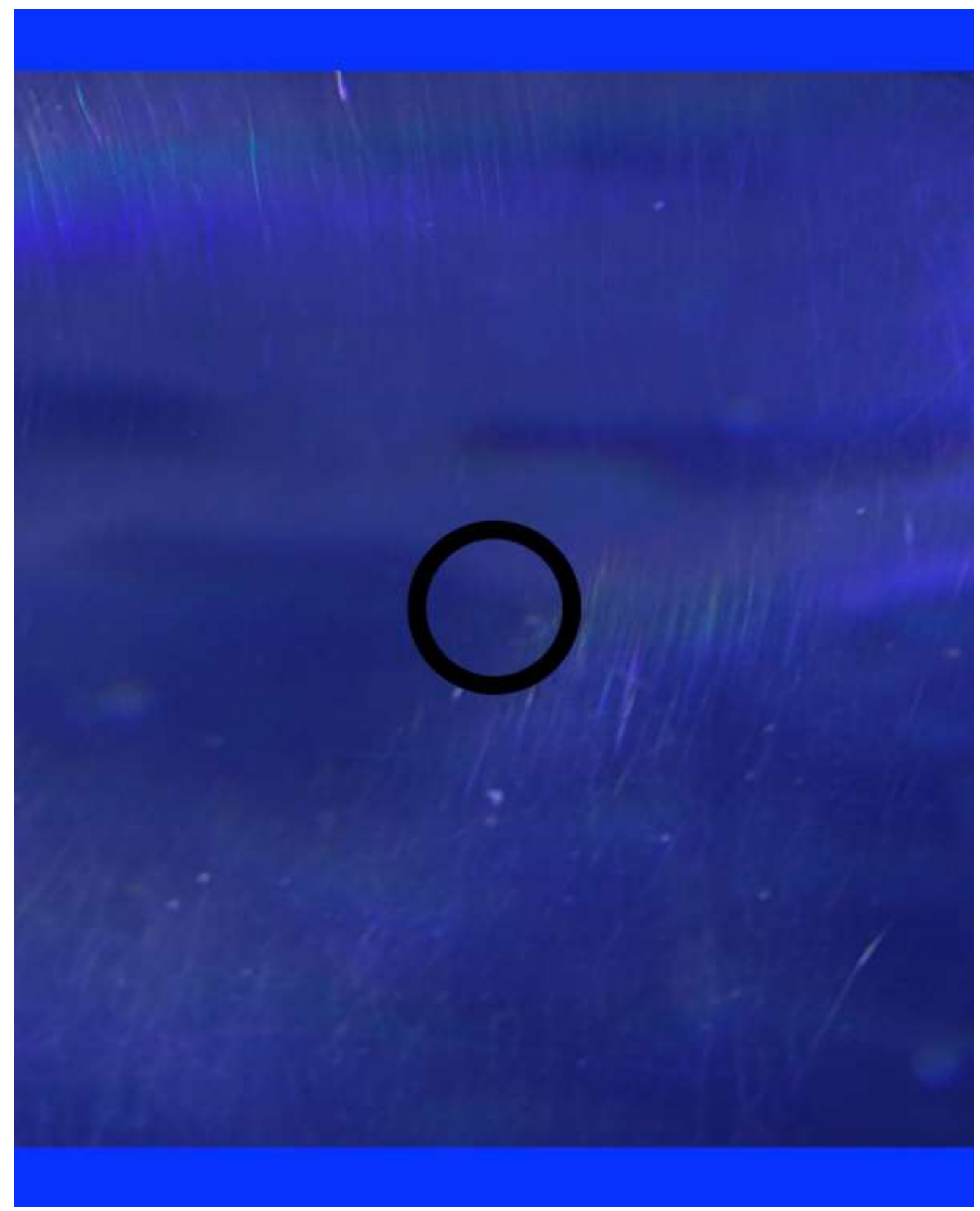


Revista de Estudios en Sociedad,

Artes y Gestión Cultural

ISSN: 2340-9096

https://doi.org/10.17561/rtc.extra5.5799

ख 0

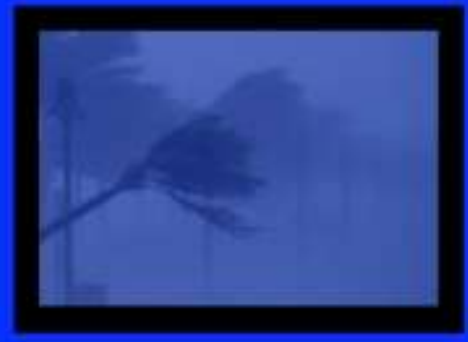

Podria esperarse que hacia el 2020 existan ya

transportes espaciales de gran capacidad para pasajeros. 
ISSN: 2340-9096

https://doi.org/10.17561/rtc.extra5.5799 ख 0
Abril 2021

[post-futuro] 
Revista de Estudios en Sociedad,

Artes y Gestión Cultural

ISSN: 2340-9096

https://doi.org/10.17561/rtc.extra5.5799

ख 0
Extraordinario V

Abril 2021

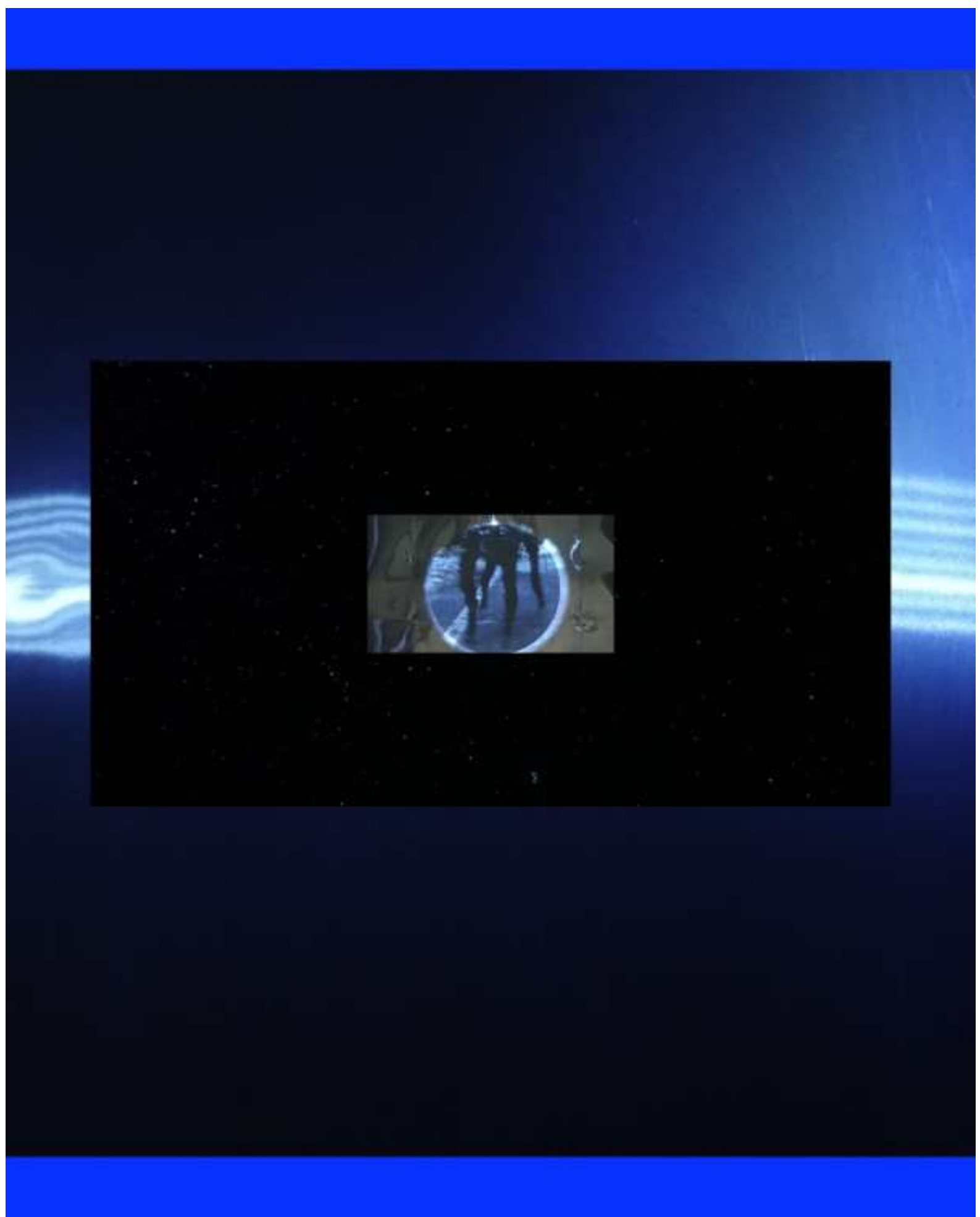


Revista de Estudios en Sociedad,

Artes y Gestión Cultural

ISSN: $2340-9096$

https://doi.org/10.17561/rtc.extra5.5799

ख 0
Extraordinario V

Abril 2021

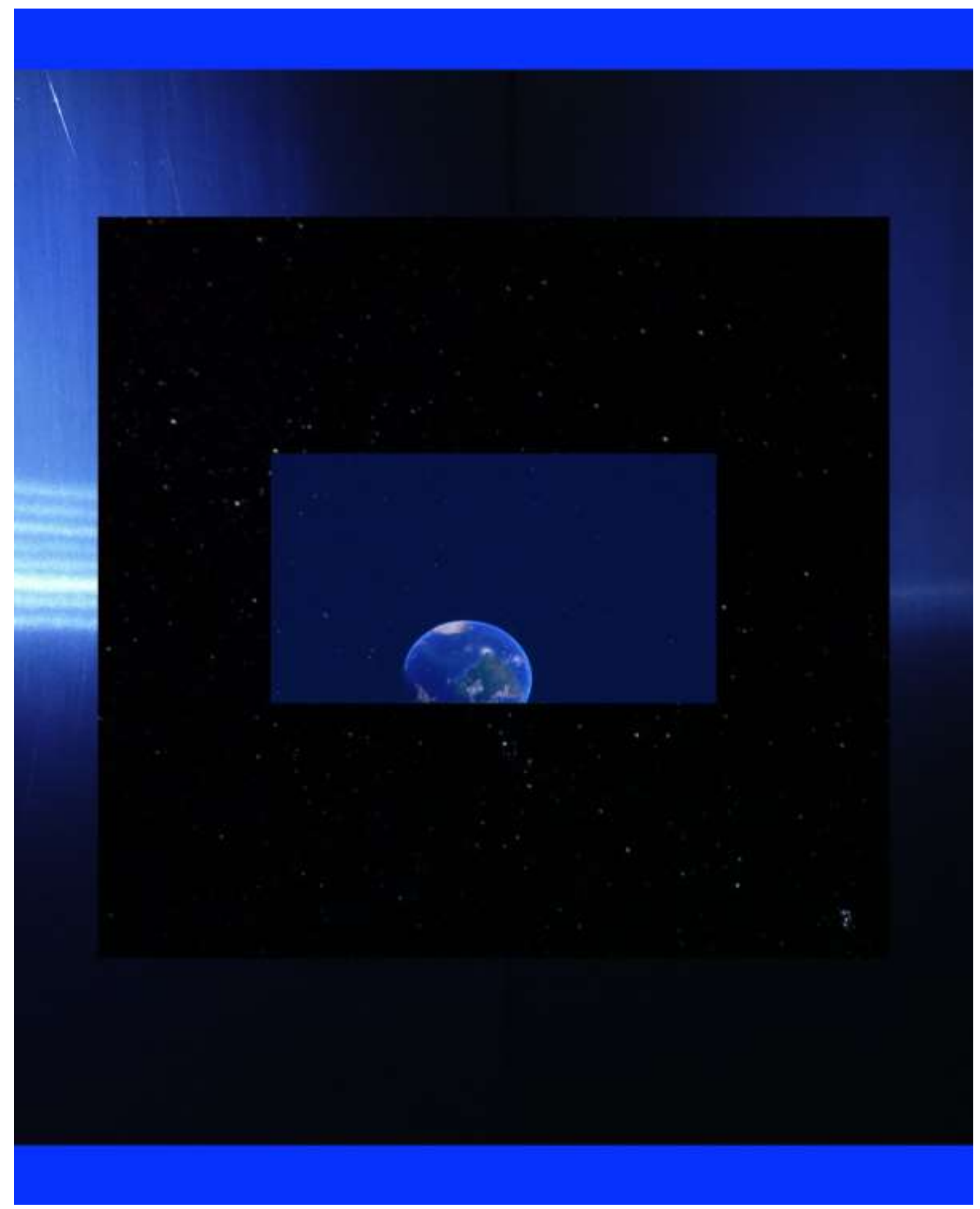




\section{Tercio Creciente}

ISSN: $2340-9096$

https://doi.org/10.17561/rtc.extra5.5799

a)
Revista de Estudios en Sociedad,

Artes y Gestión Cultural

Extraordinario V

Abril 2021

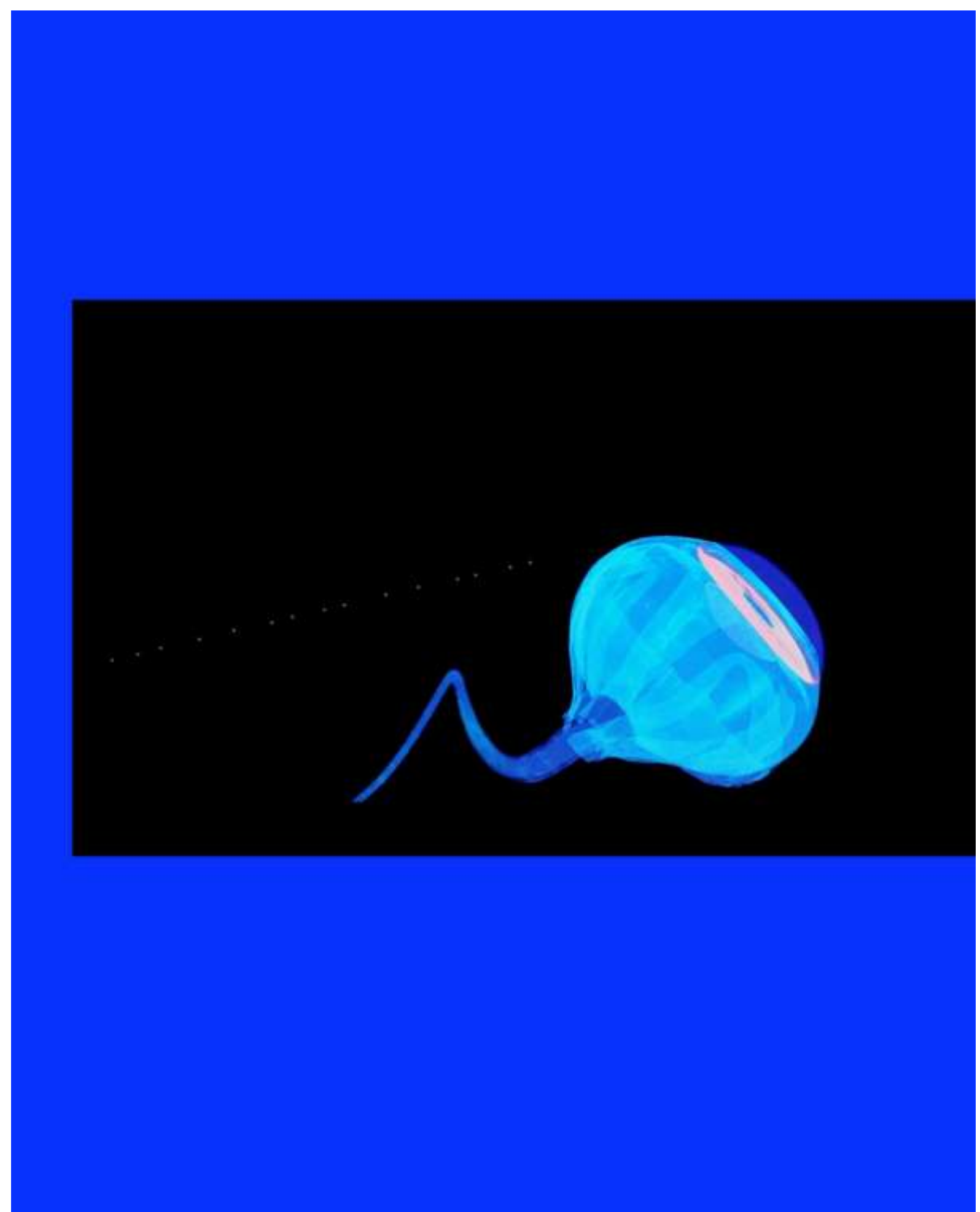


ISSN: $2340-9096$

https://doi.org/10.17561/rtc.extra5.5799

a)
Revista de Estudios en Sociedad,

Artes y Gestión Cultural

Extraordinario V

Abril 2021

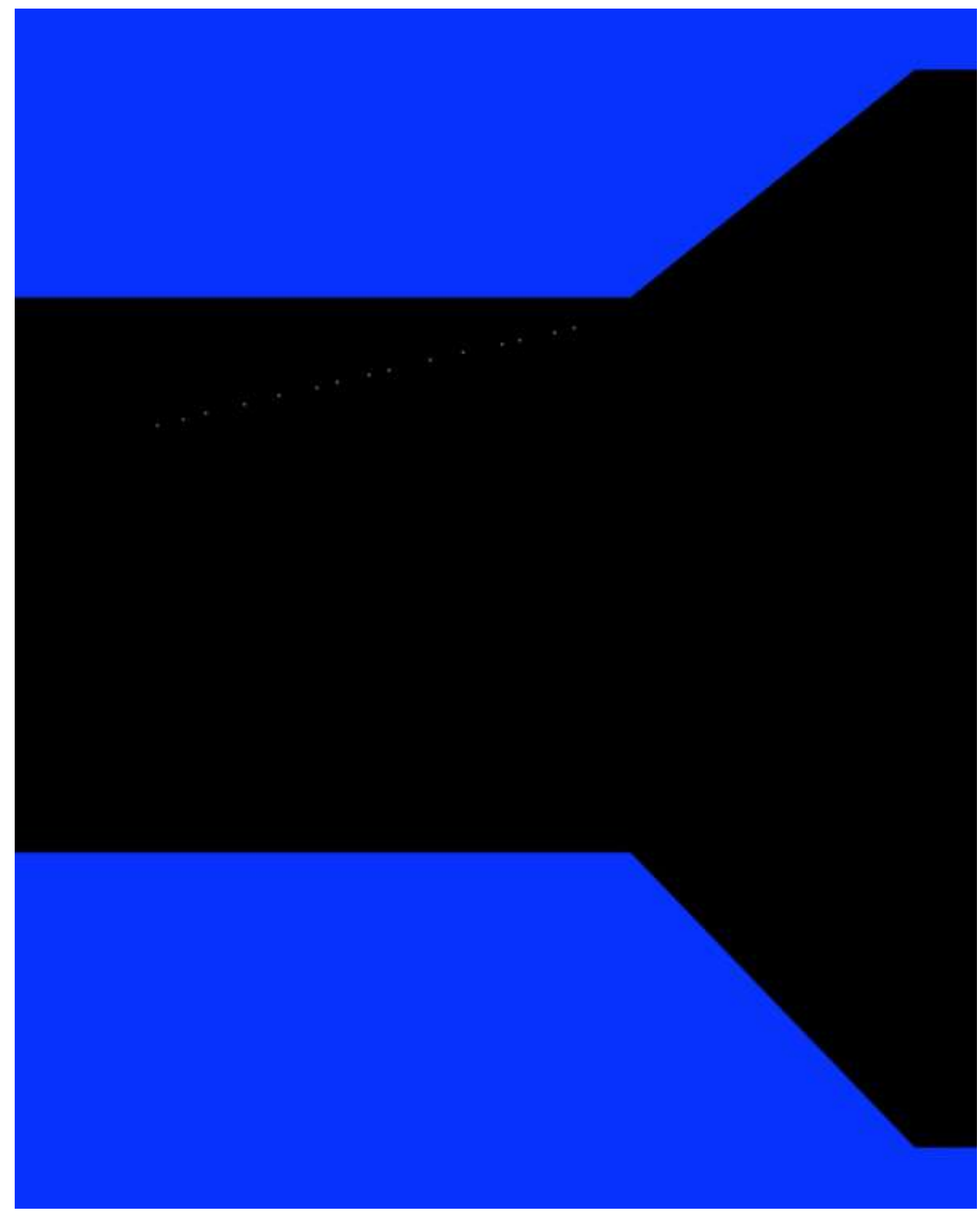




\section{Tercio Creciente}

ISSN: 2340-9096

https://doi.org/10.17561/rtc.extra5.5799

(x) $\alpha$
Revista de Estudios en Sociedad,

Artes y Gestión Cultural
Monográfico

Extraordinario V

Abril 2021

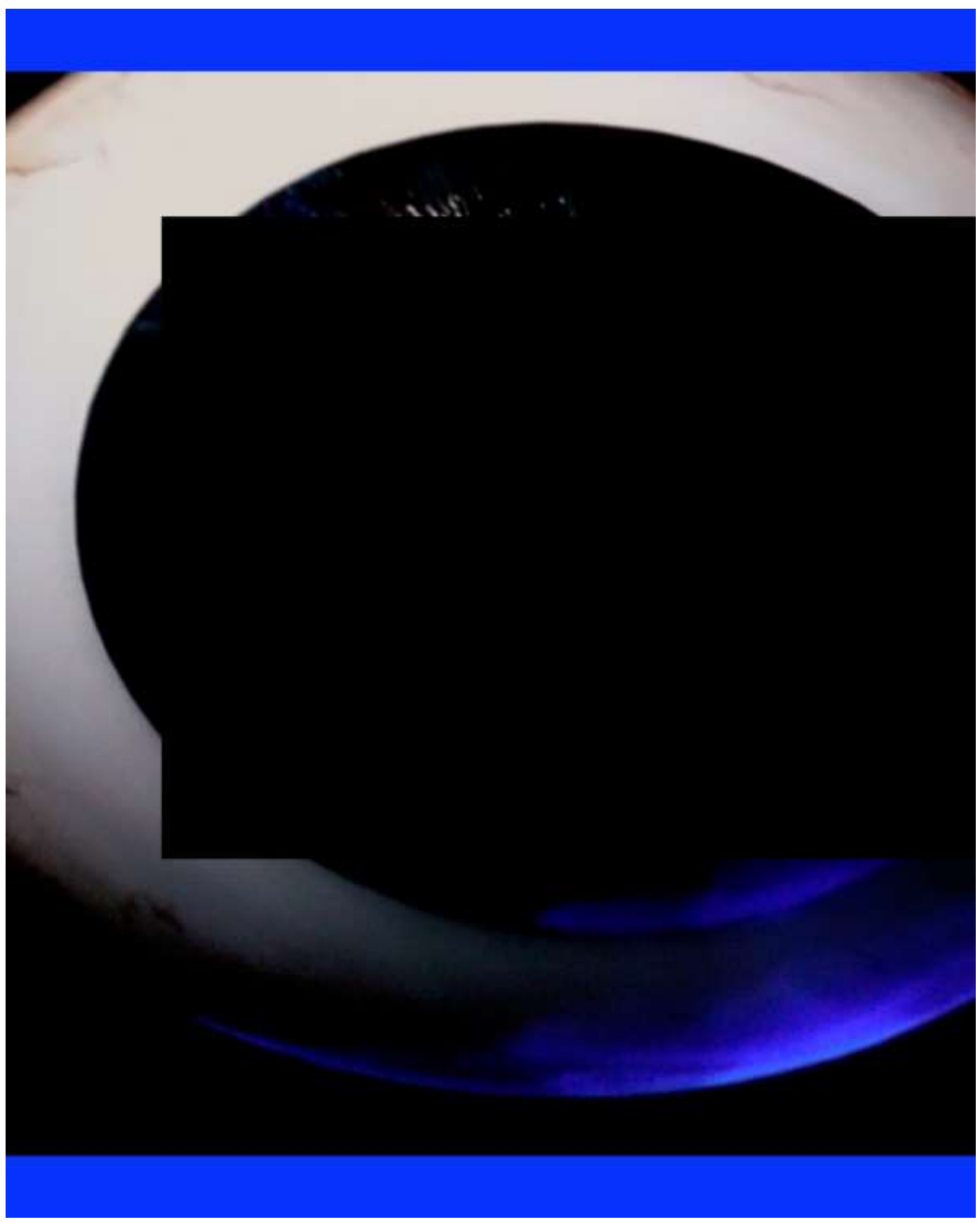


Tercio Creciente

ISSN: 2340-9096

https://doi.org/10.17561/rtc.extra5.5799

अ
Revista de Estudios en Sociedad,

Artes y Gestión Cultural

Monográfico

Extraordinario V

Abril 2021

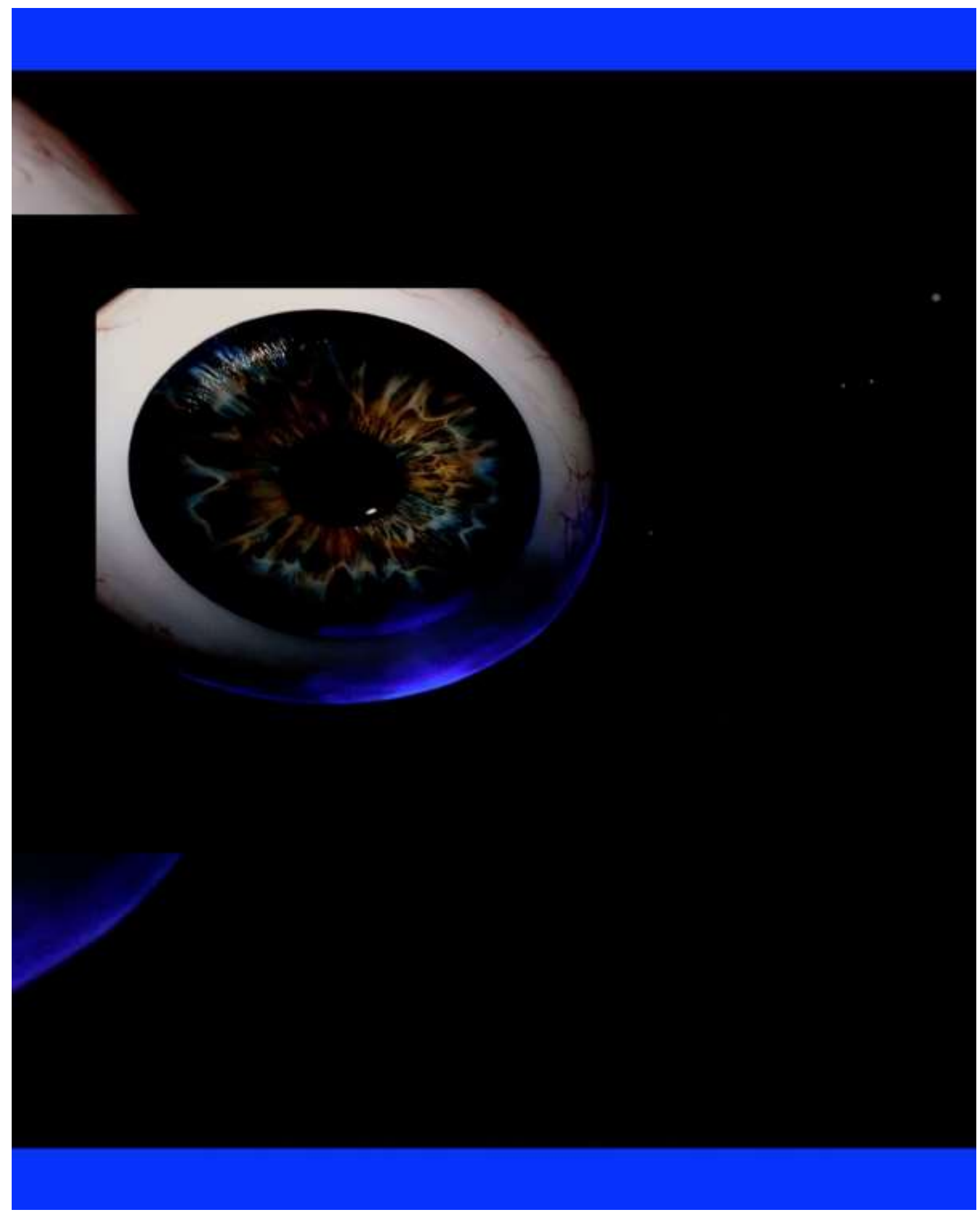




\section{Tercio Creciente}

ISSN: 2340-9096

https://doi.org/10.17561/rtc.extra5.5799

(x)
Revista de Estudios en Sociedad, Artes y Gestión Cultural
Monográfico

Extraordinario V

Abril 2021

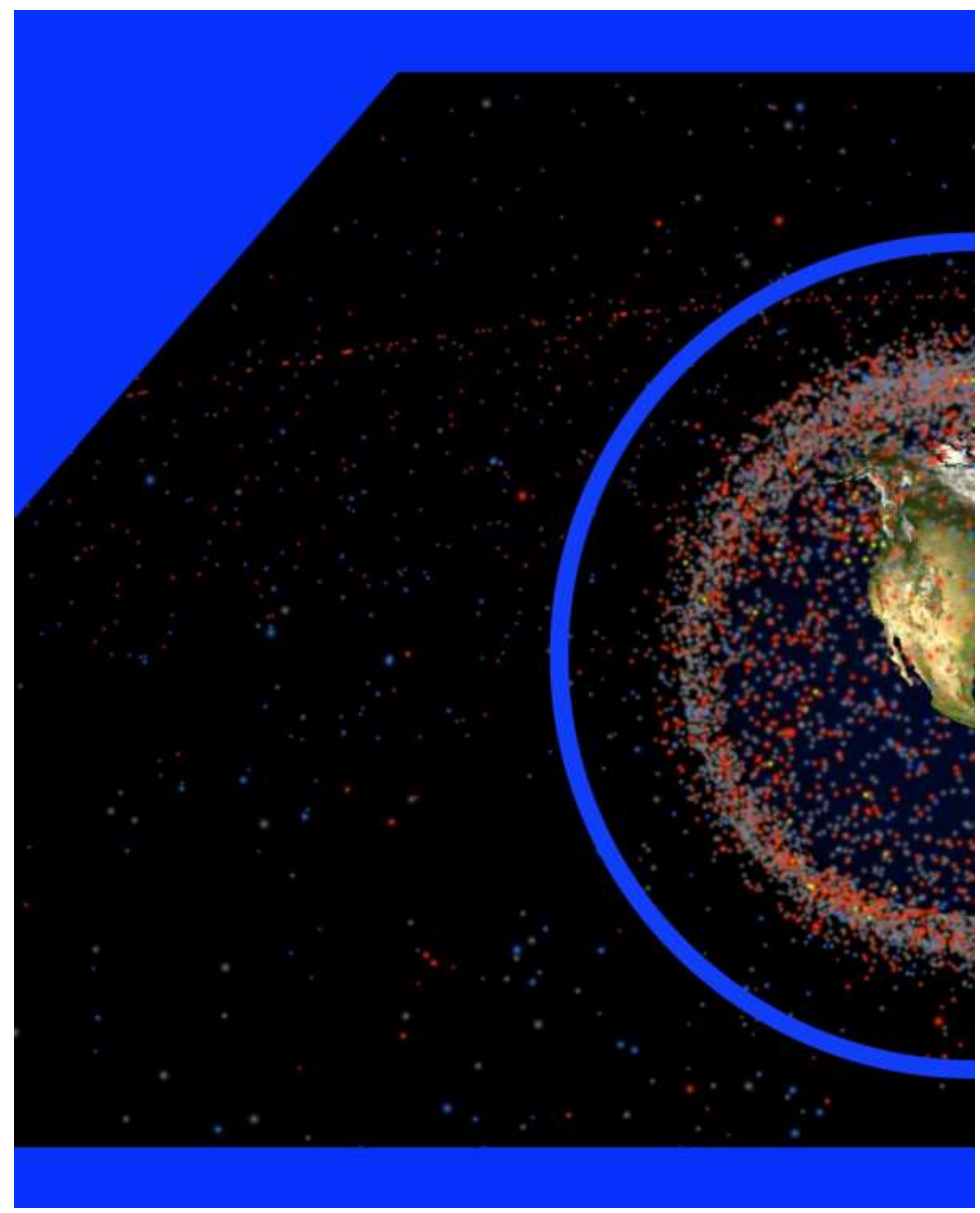




\section{Tercio Creciente}

ISSN: 2340-9096

https://doi.org/10.17561/rtc.extra5.5799 ख) $\alpha$
Revista de Estudios en Sociedad, Artes y Gestión Cultural

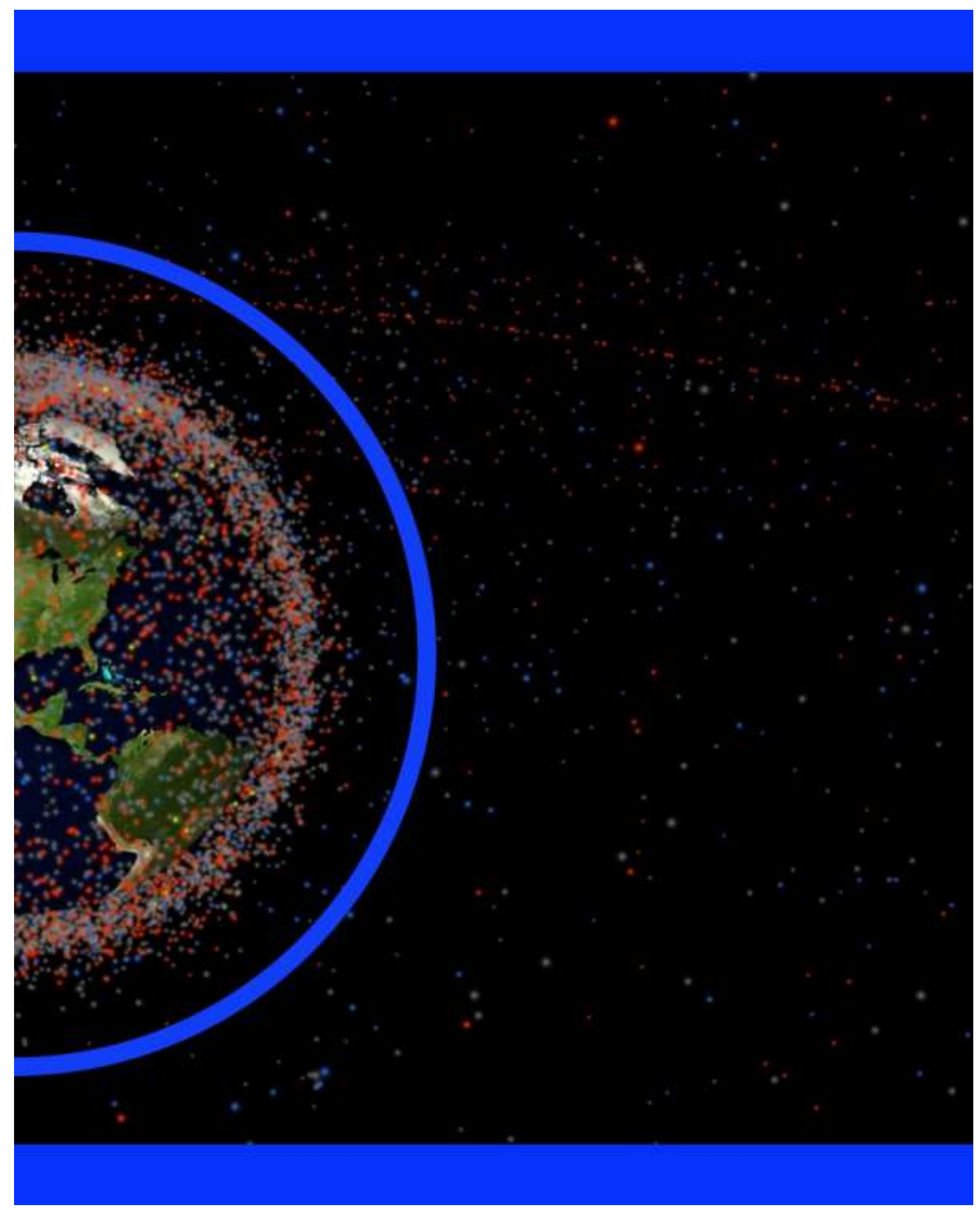




\section{Tercio Creciente}

ISSN: $2340-9096$

https://doi.org/10.17561/rtc.extra5.5799

a)
Revista de Estudios en Sociedad,

Artes y Gestión Cultural
Monográfico

Extraordinario V

Abril 2021

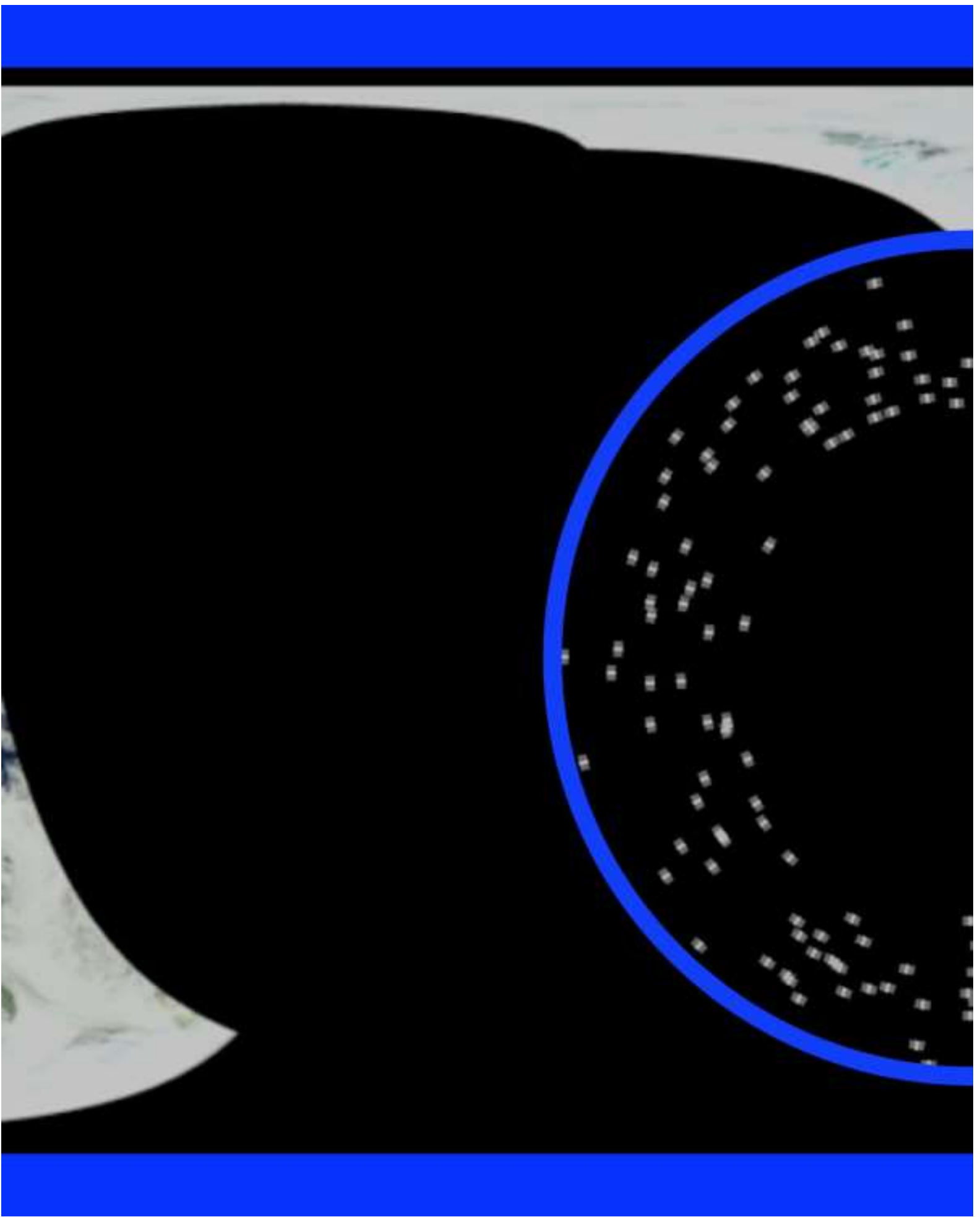




\section{Tercio Creciente}

ISSN: $2340-9096$

https://doi.org/10.17561/rtc.extra5.5799

(x)
Revista de Estudios en Sociedad, Artes y Gestión Cultural
Monográfico

Extraordinario V

Abril 2021

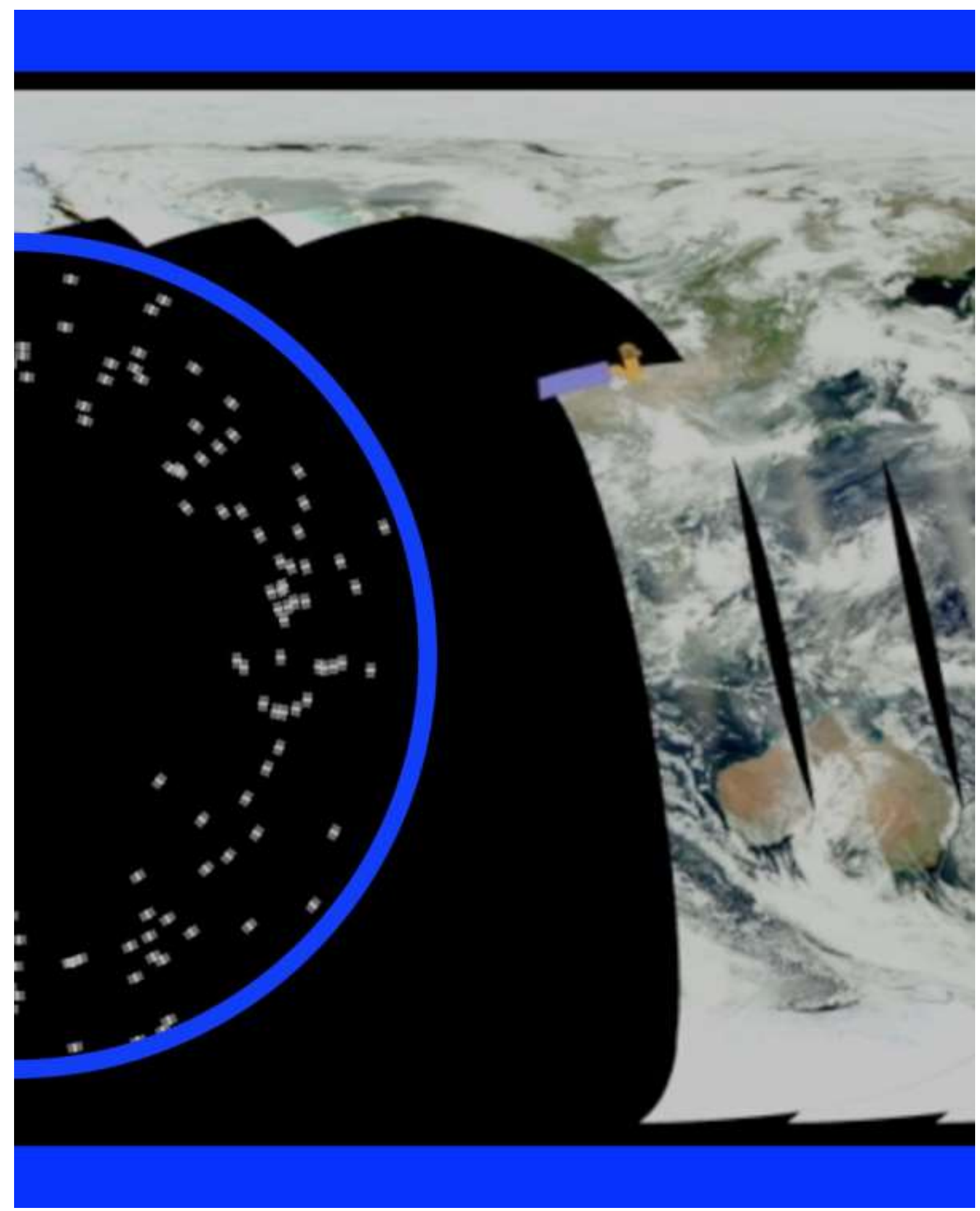


ISSN: $2340-9096$

https://doi.org/10.17561/rtc.extra5.5799

ख)
Revista de Estudios en Sociedad,

Artes y Gestión Cultural
Monográfico

Extraordinario V

Abril 2021

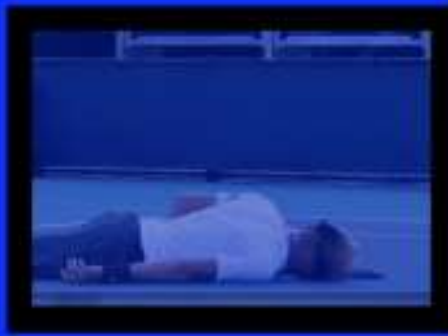

Las posibilidades de la tecnologia espacial superan con mucho a las de la aviación. Una sociedad altamente desarrollada quizá sea capaz de funcionar sin aeroplanos, pero no podrá funcionar con eficacia si careciera de satélites de comunicaciones. (...) A largo plazo el conocimiento cientifico es el más valioso, y con frecuencia la más rentable de las inversiones. *

"Extracto del prajogo de Arthur C. Clarke en el libro "Exploración del espacio". Edigiones Ourto. Bercelona 1985 
ISSN: 2340-9096

https://doi.org/10.17561/rtc.extra5.5799 ख 0
Abril 2021

[colapso] 


\section{Tercio Creciente}

ISSN: $2340-9096$

https://doi.org/10.17561/rtc.extra5.5799

(x)
Revista de Estudios en Sociedad, Artes y Gestión Cultural

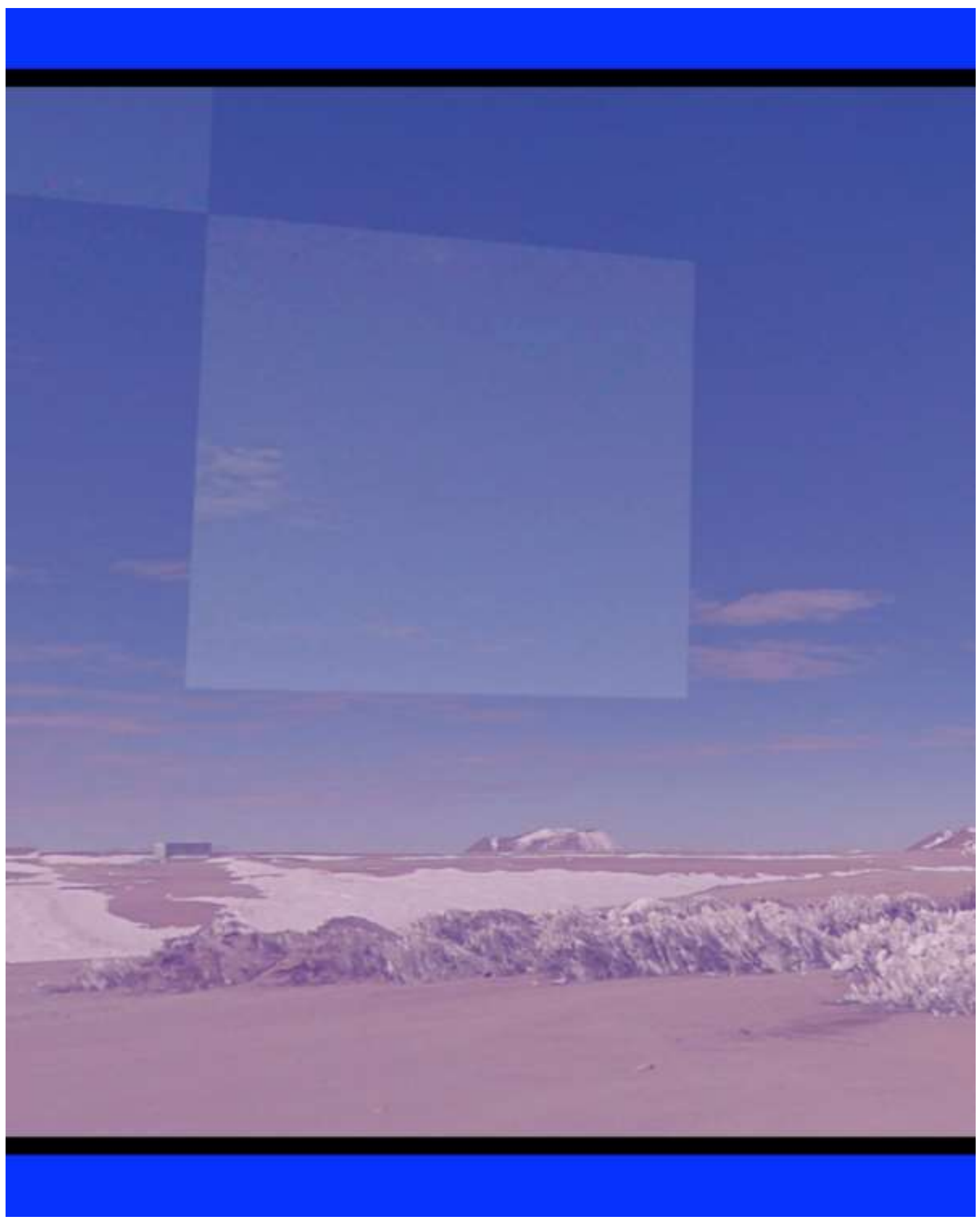




\section{Tercio Creciente}

ISSN: $2340-9096$

https://doi.org/10.17561/rtc.extra5.5799

ख 0
Revista de Estudios en Sociedad, Artes y Gestión Cultural
Monográfico

Extraordinario V

Abril 2021

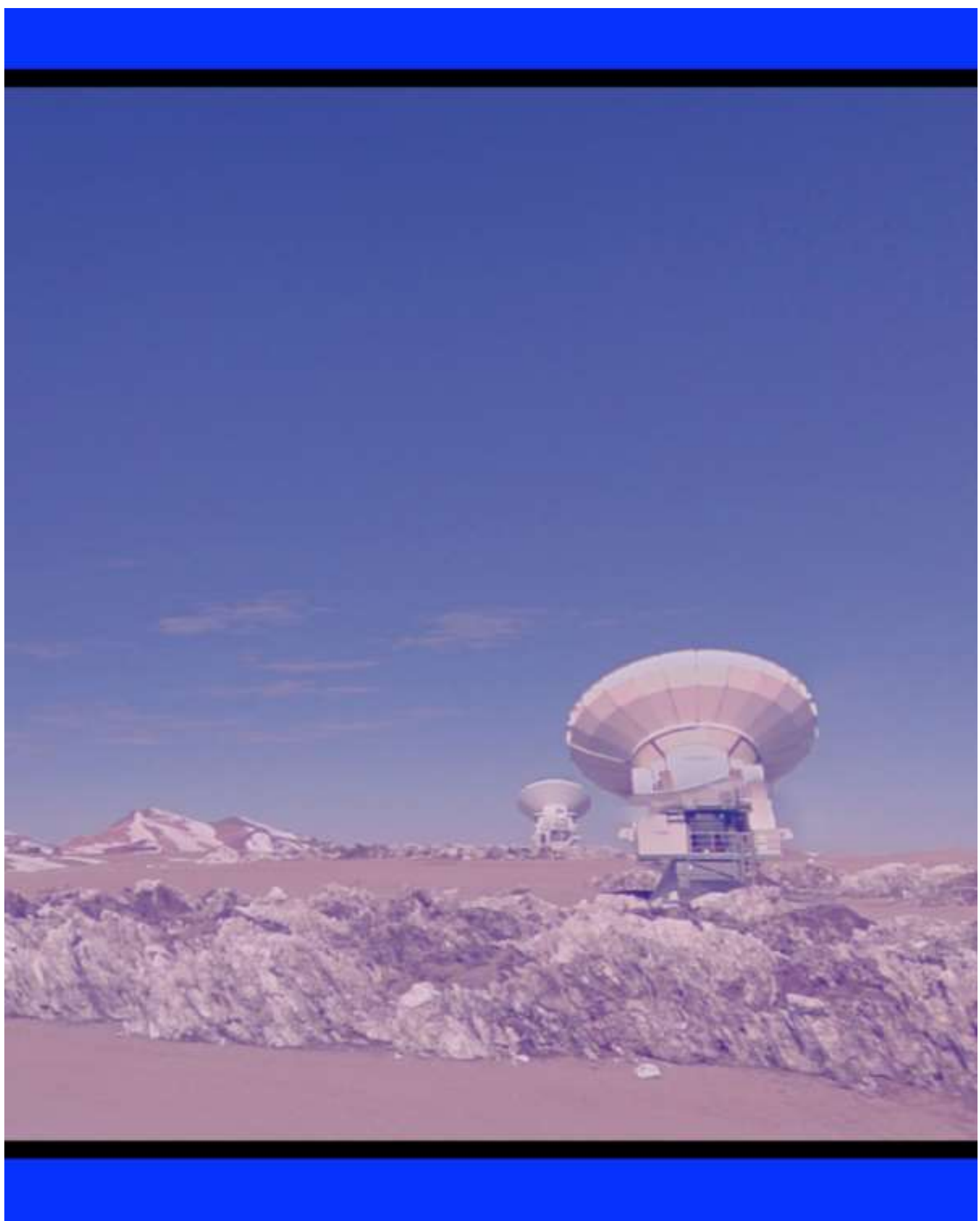




\section{Tercio Creciente}

ISSN: $2340-9096$

https://doi.org/10.17561/rtc.extra5.5799

(x)
Revista de Estudios en Sociedad,

Artes y Gestión Cultural
Monográfico

Extraordinario V

Abril 2021

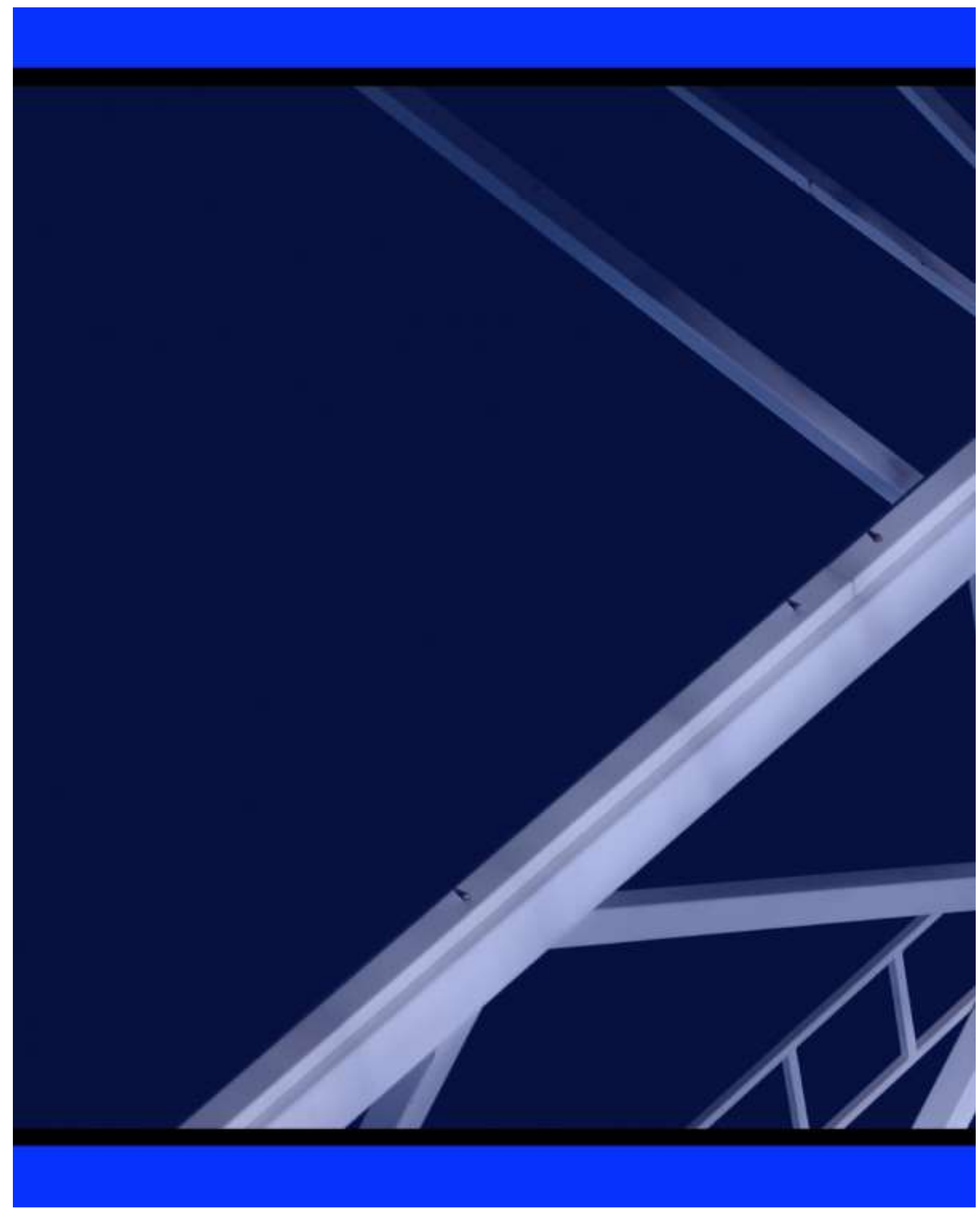




\section{Tercio Creciente}

ISSN: $2340-9096$

https://doi.org/10.17561/rtc.extra5.5799

(9)

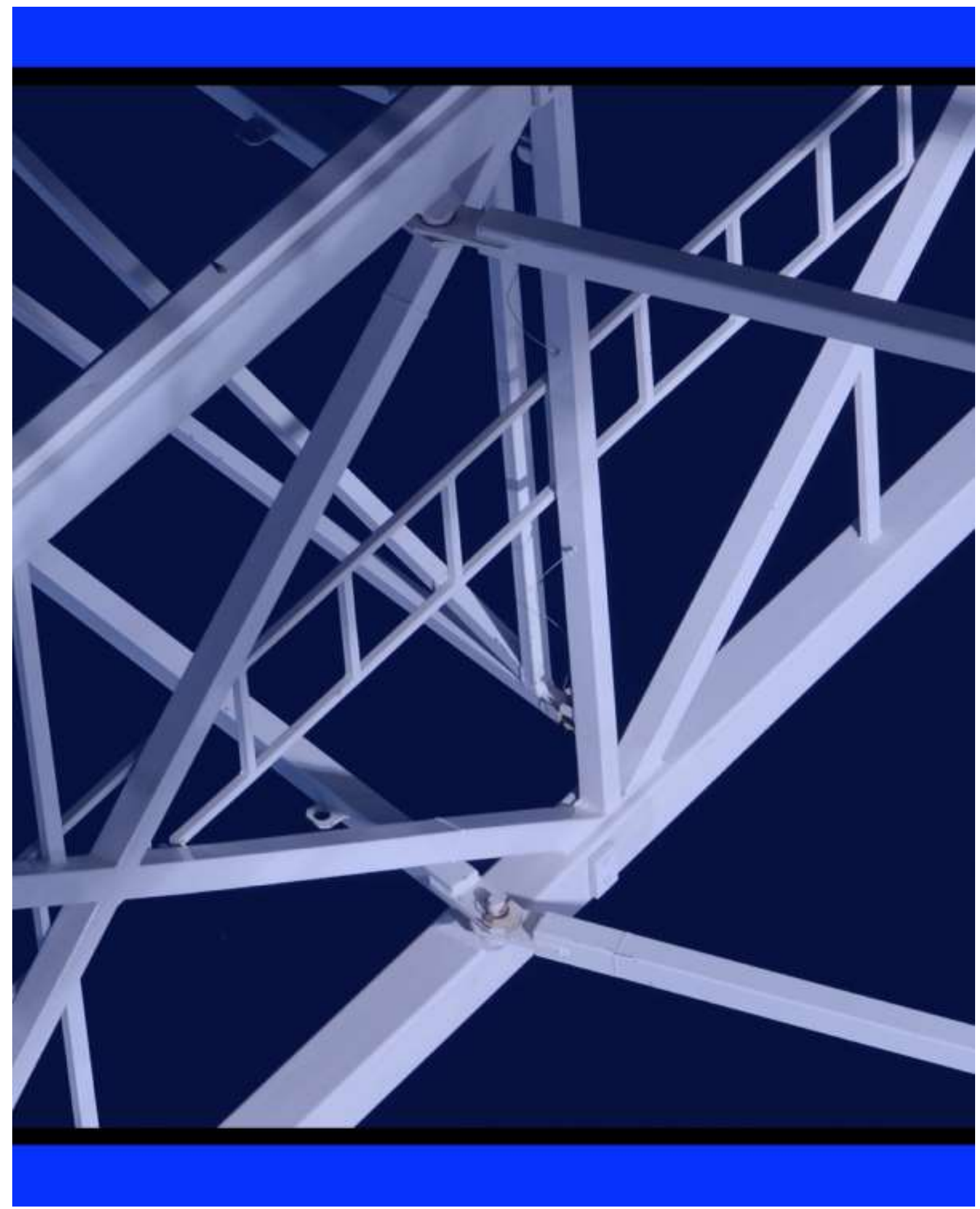




\section{Tercio Creciente}

ISSN: 2340-9096

https://doi.org/10.17561/rtc.extra5.5799

ख 0
Revista de Estudios en Sociedad,

Artes y Gestión Cultural

Extraordinario V

Abril 2021

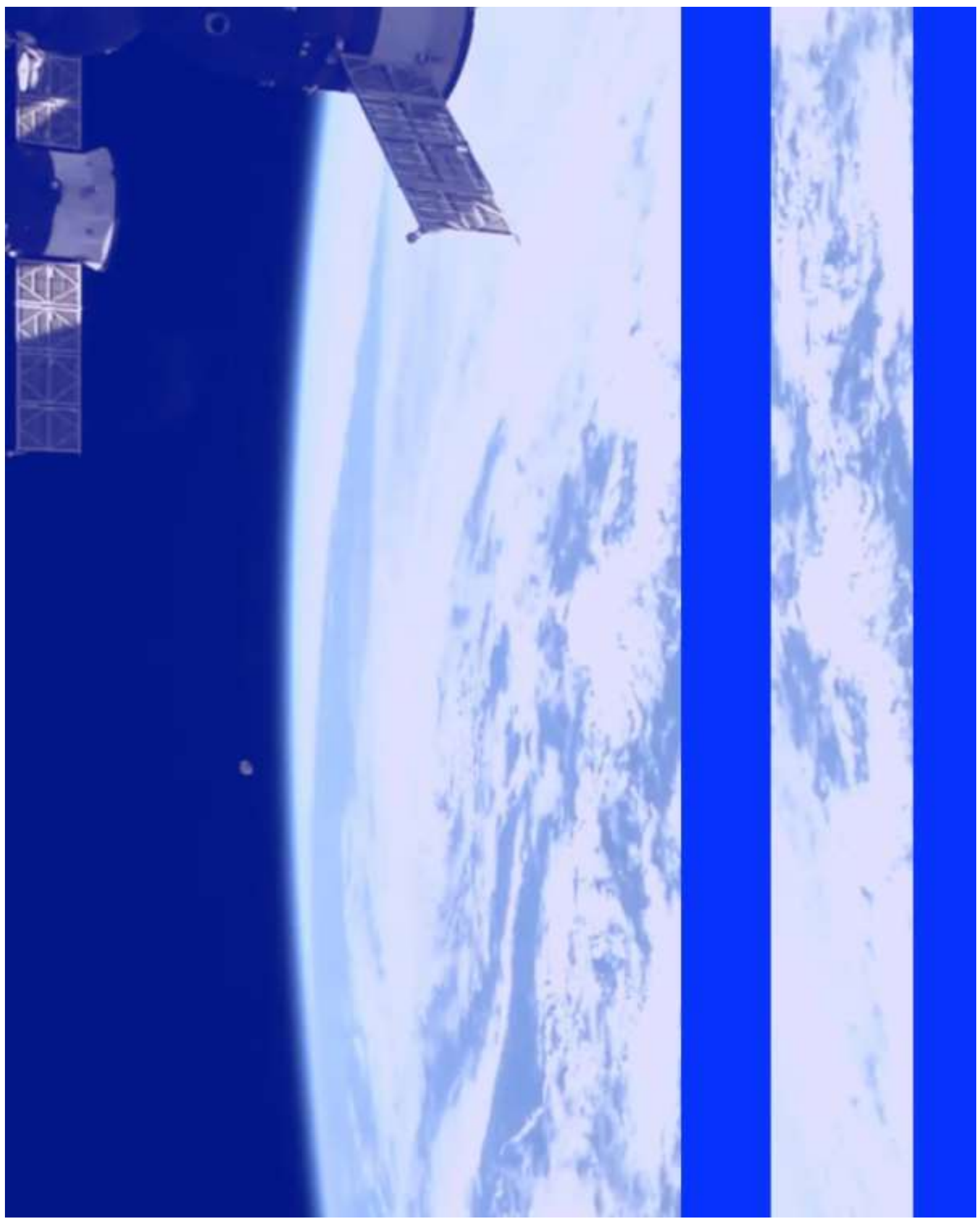




\section{Tercio Creciente}

ISSN: $2340-9096$

https://doi.org/10.17561/rtc.extra5.5799

(x) $\alpha$
Revista de Estudios en Sociedad, Artes y Gestión Cultural

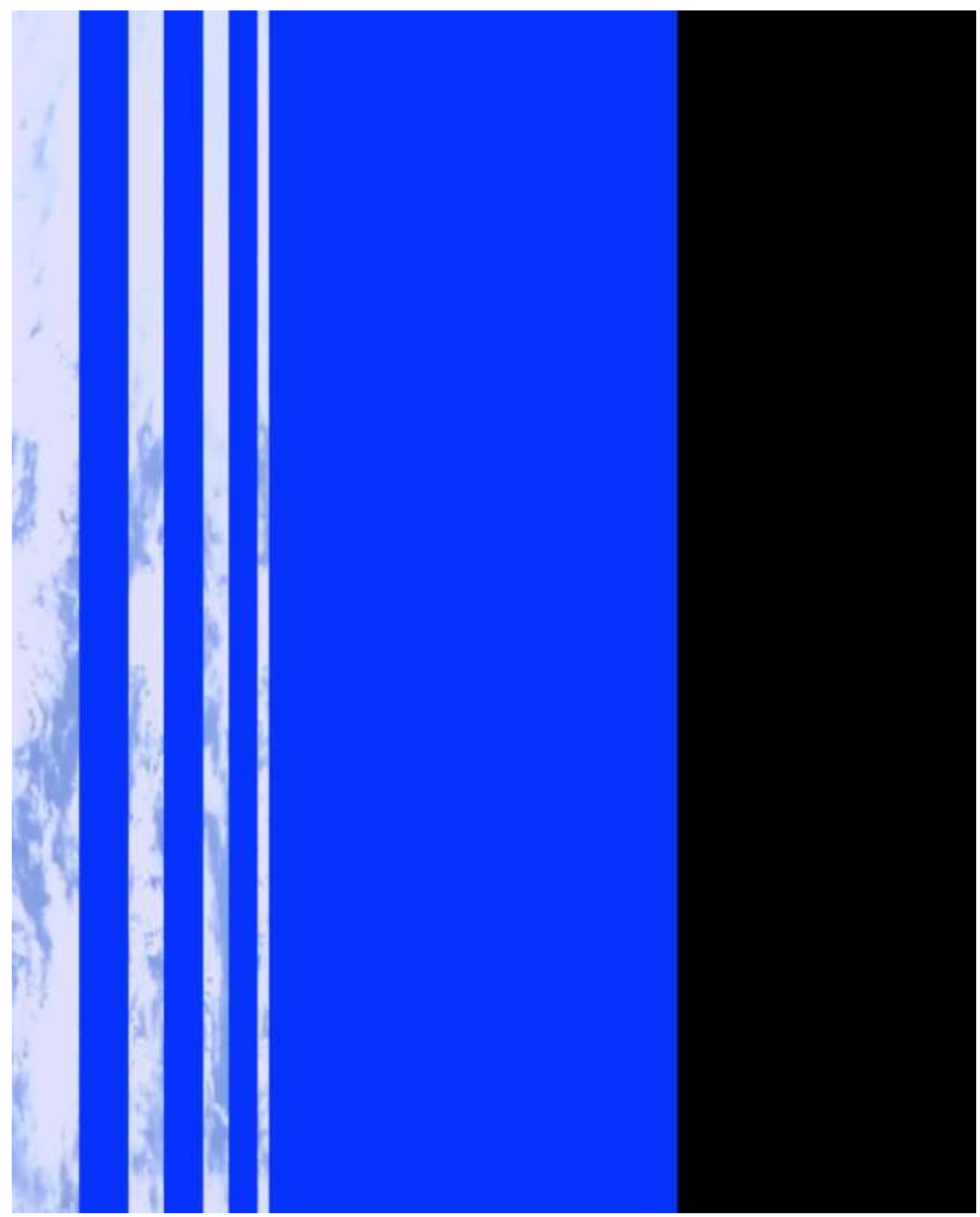


Revista de Estudios en Sociedad, Artes y Gestión Cultural

ISSN: 2340-9096

https://doi.org/10.17561/rtc.extra5.5799

ख 0

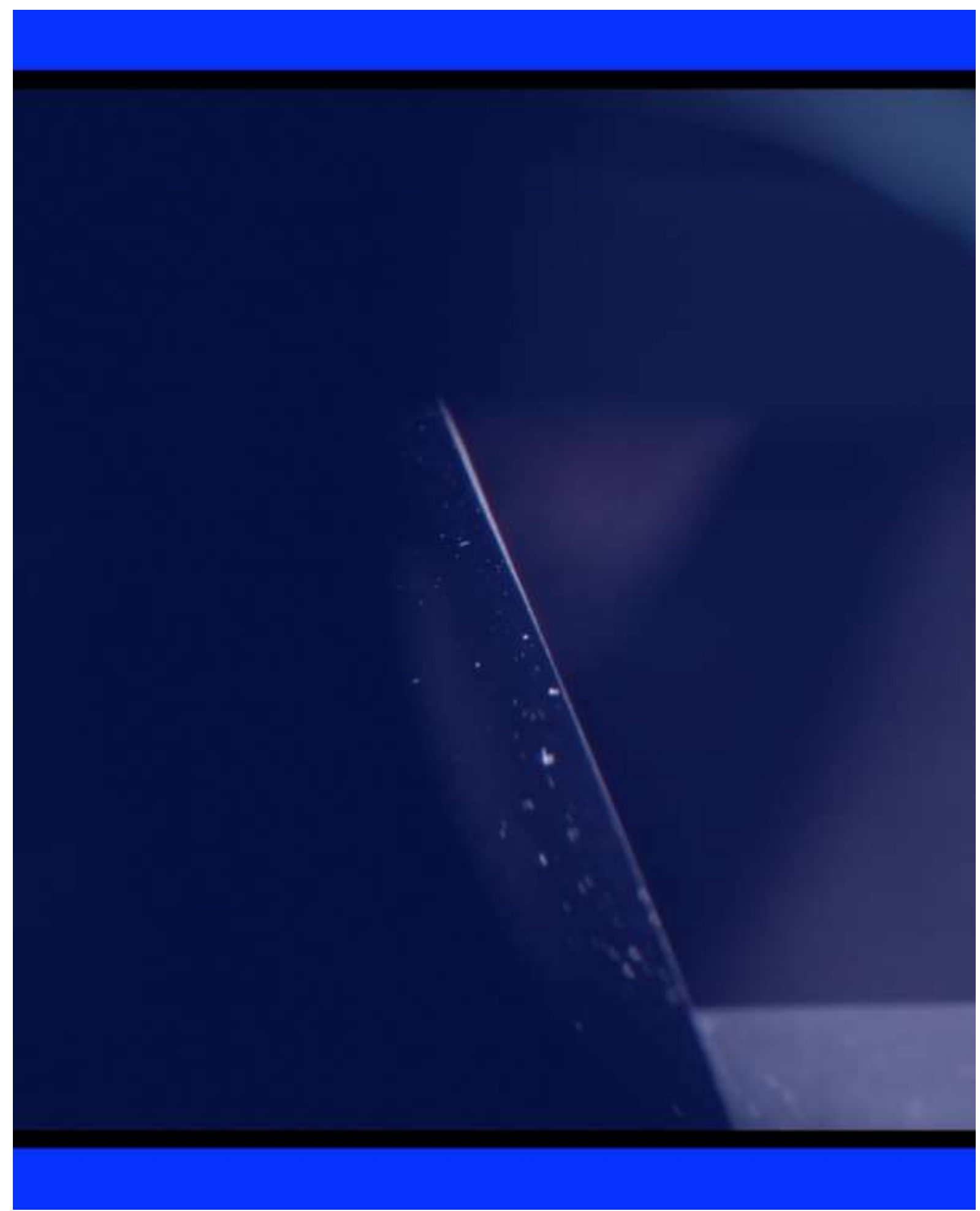




\section{Tercio Creciente}

ISSN: $2340-9096$

https://doi.org/10.17561/rtc.extra5.5799

a)
Revista de Estudios en Sociedad,

Artes y Gestión Cultural

Monográfico

Extraordinario V

Abril 2021

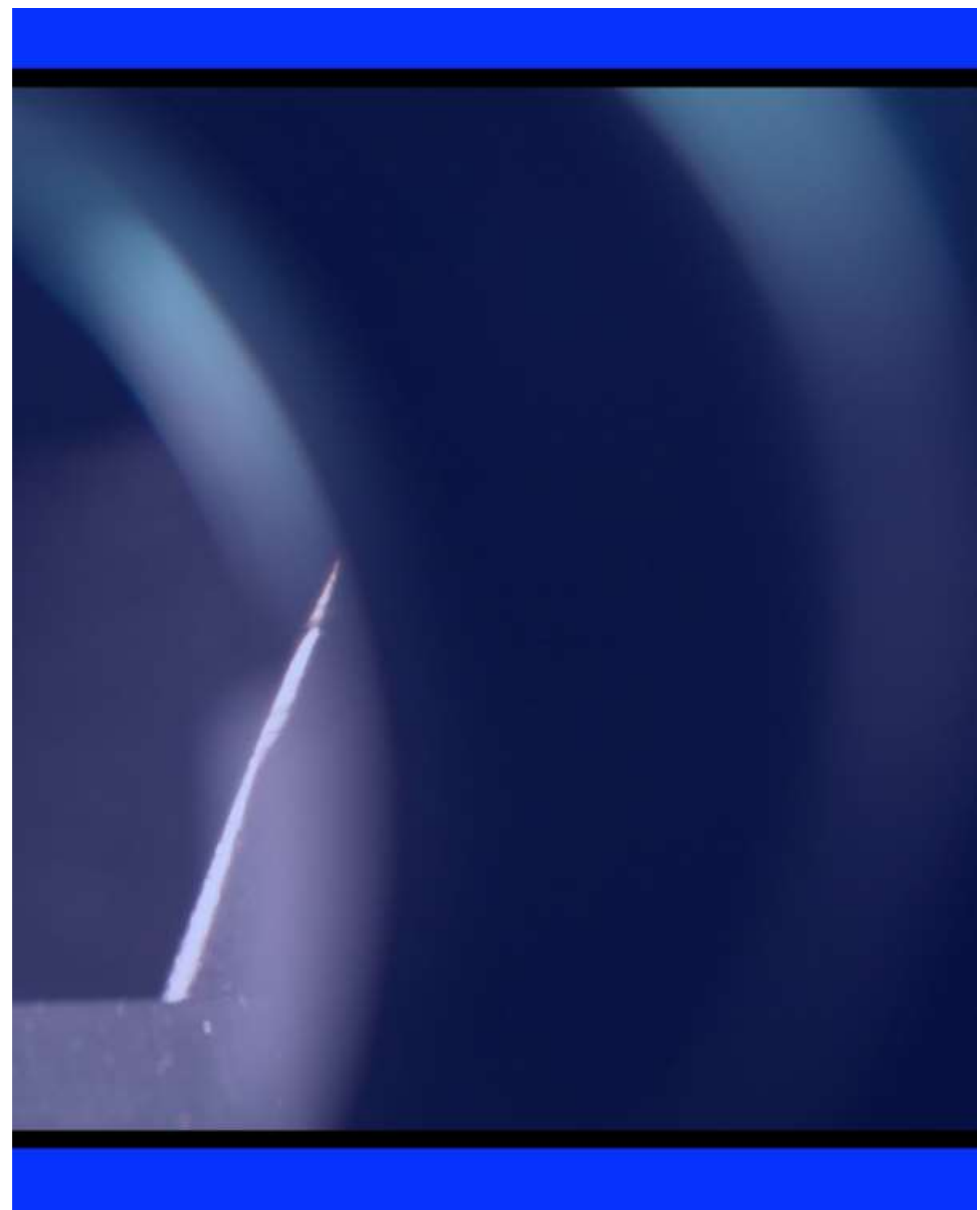




\section{Tercio Creciente}

ISSN: $2340-9096$

https://doi.org/10.17561/rtc.extra5.5799

ख 0
Revista de Estudios en Sociedad,

Artes y Gestión Cultural

\section{Abril 2021}

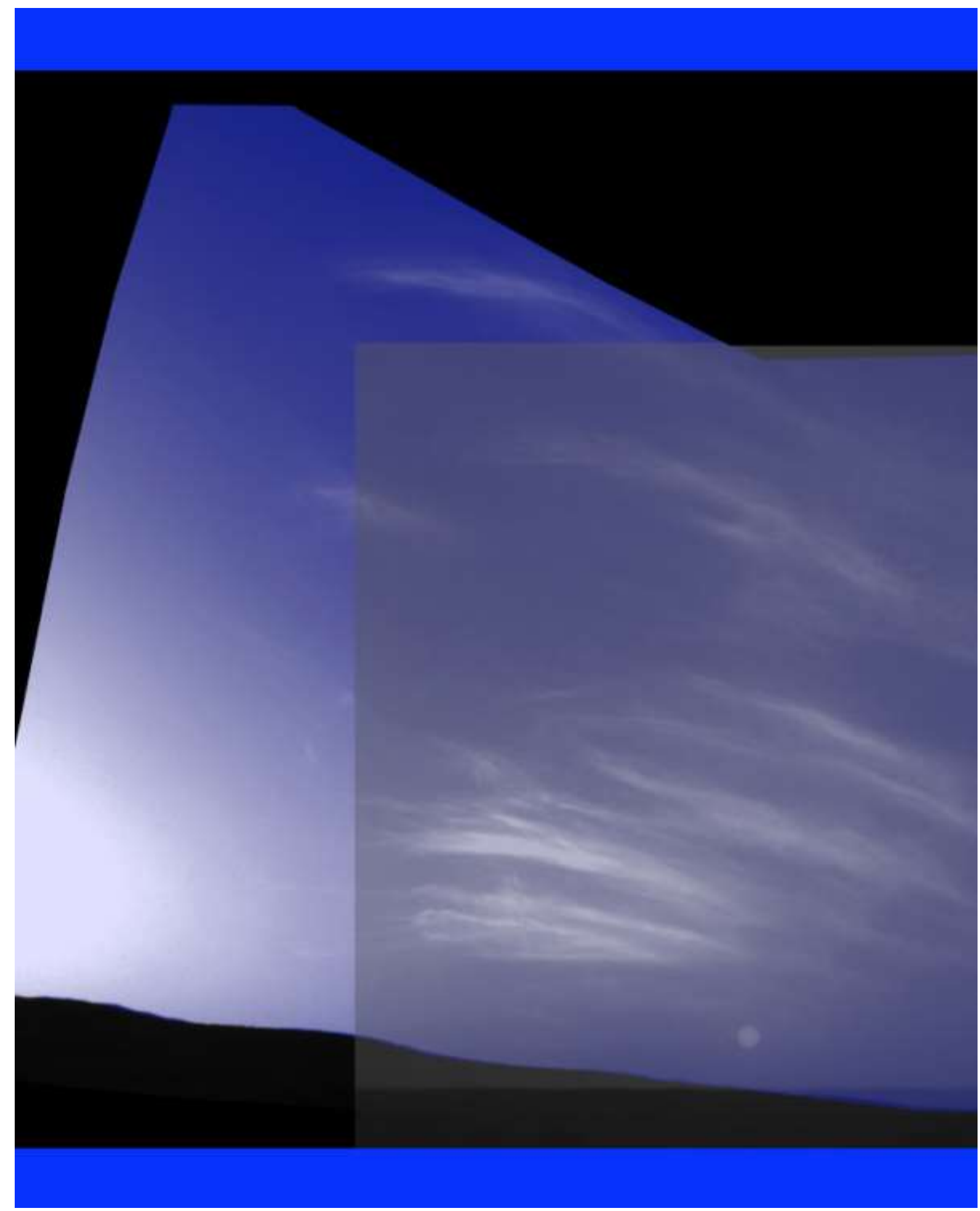


ISSN: 2340-9096

https://doi.org/10.17561/rtc.extra5.5799 ख)
Revista de Estudios en Sociedad, Artes y Gestión Cultural

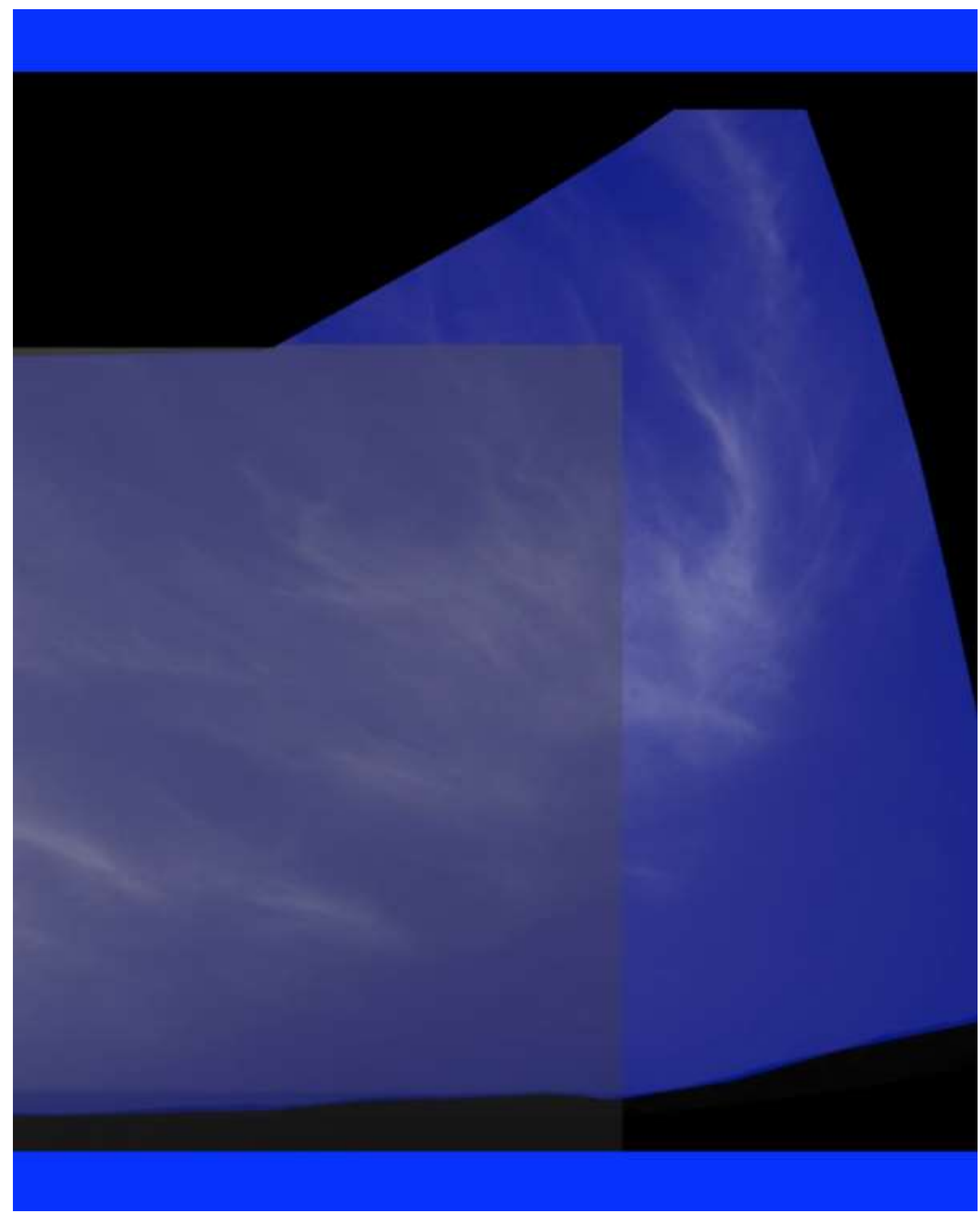




\section{Tercio Creciente}

ISSN: $2340-9096$

https://doi.org/10.17561/rtc.extra5.5799

ख 0
Revista de Estudios en Sociedad,

Artes y Gestión Cultural

Monográfico

Extraordinario V

Abril 2021

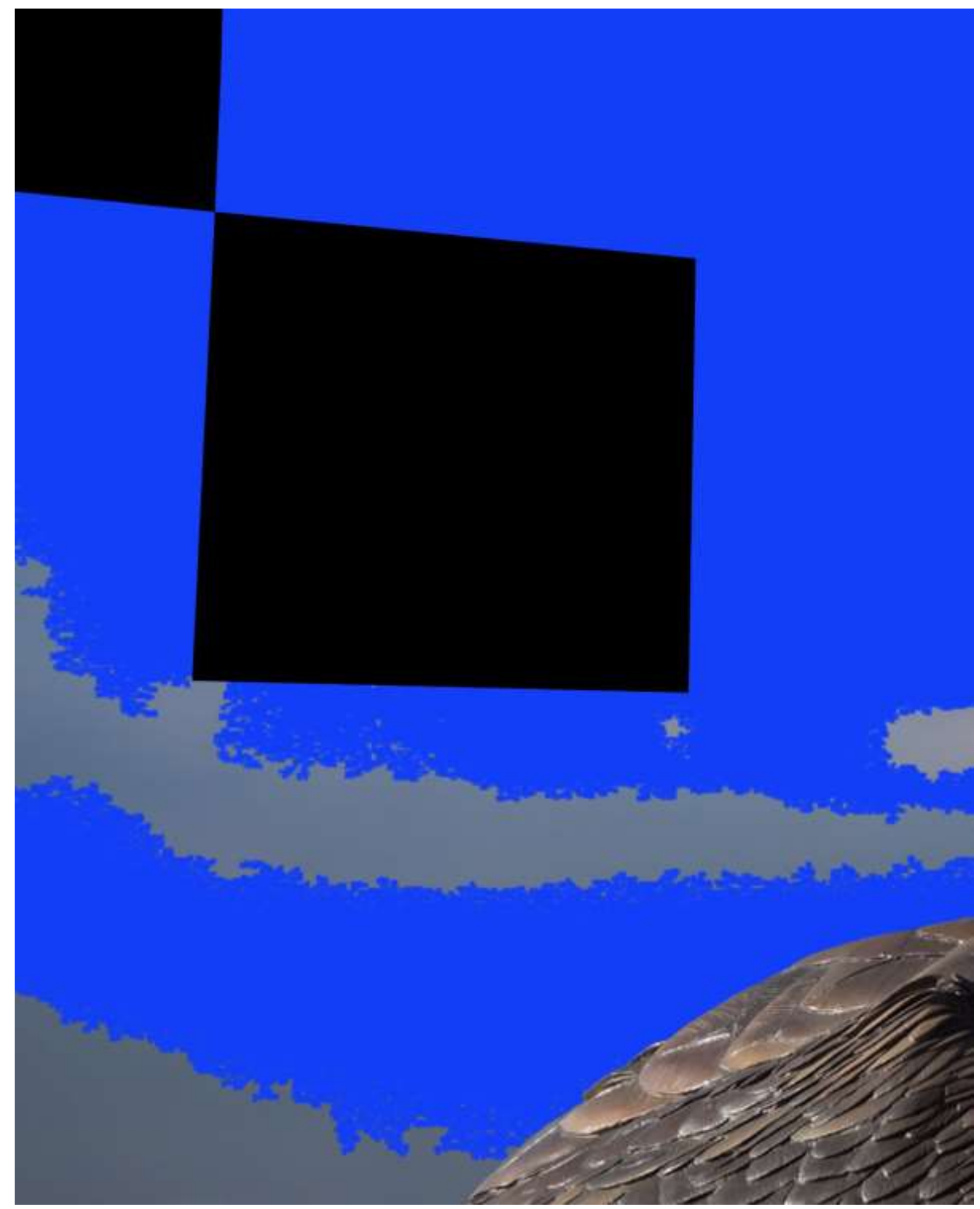




\section{Tercio Creciente}

ISSN: 2340-9096

https://doi.org/10.17561/rtc.extra5.5799

$x ;$
Revista de Estudios en Sociedad, Artes y Gestión Cultural
Monográfico

Extraordinario V

Abril 2021

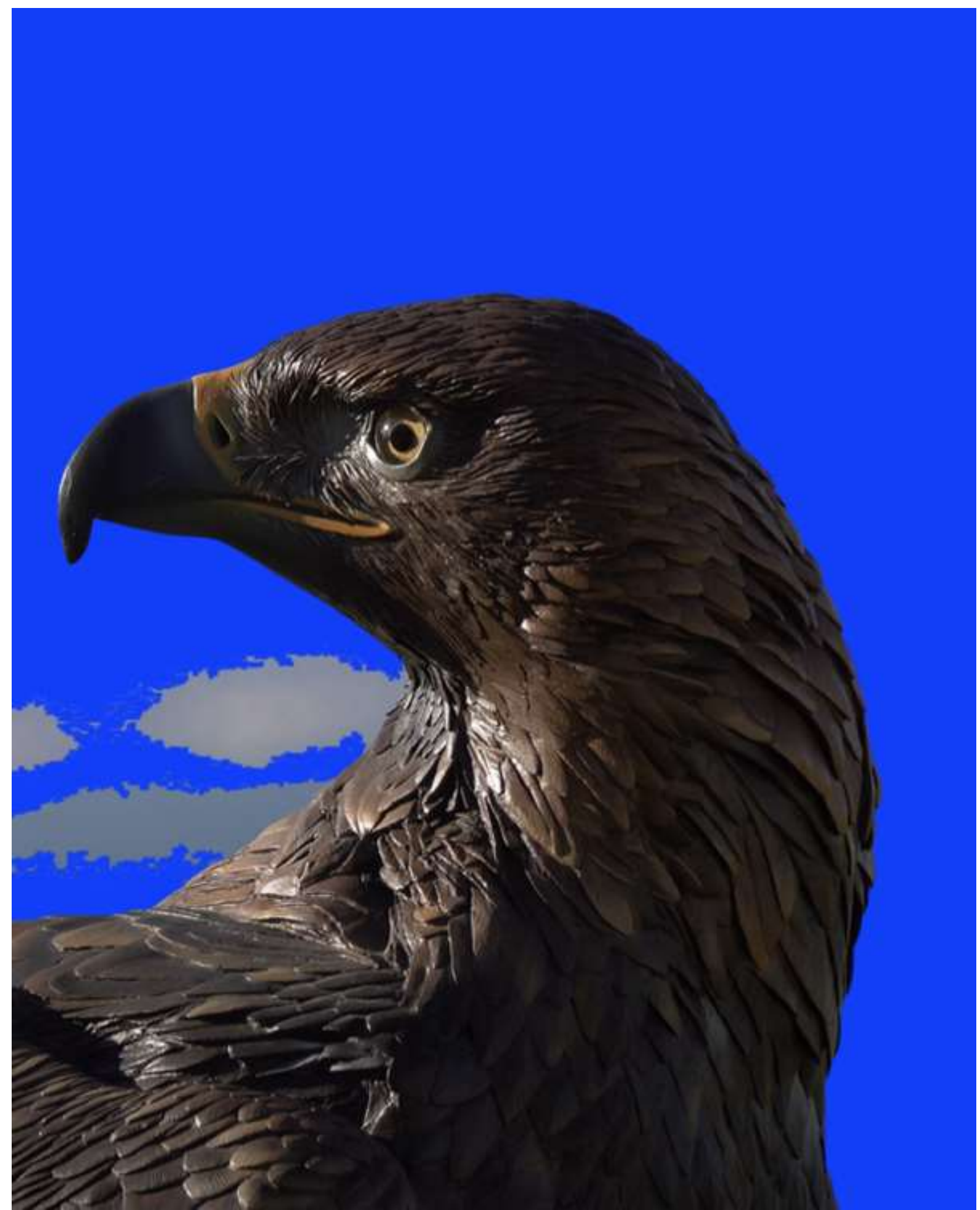




\section{Tercio Creciente}

ISSN: $2340-9096$

https://doi.org/10.17561/rtc.extra5.5799

a)
Revista de Estudios en Sociedad,

Artes y Gestión Cultural

Extraordinario V

Abril 2021

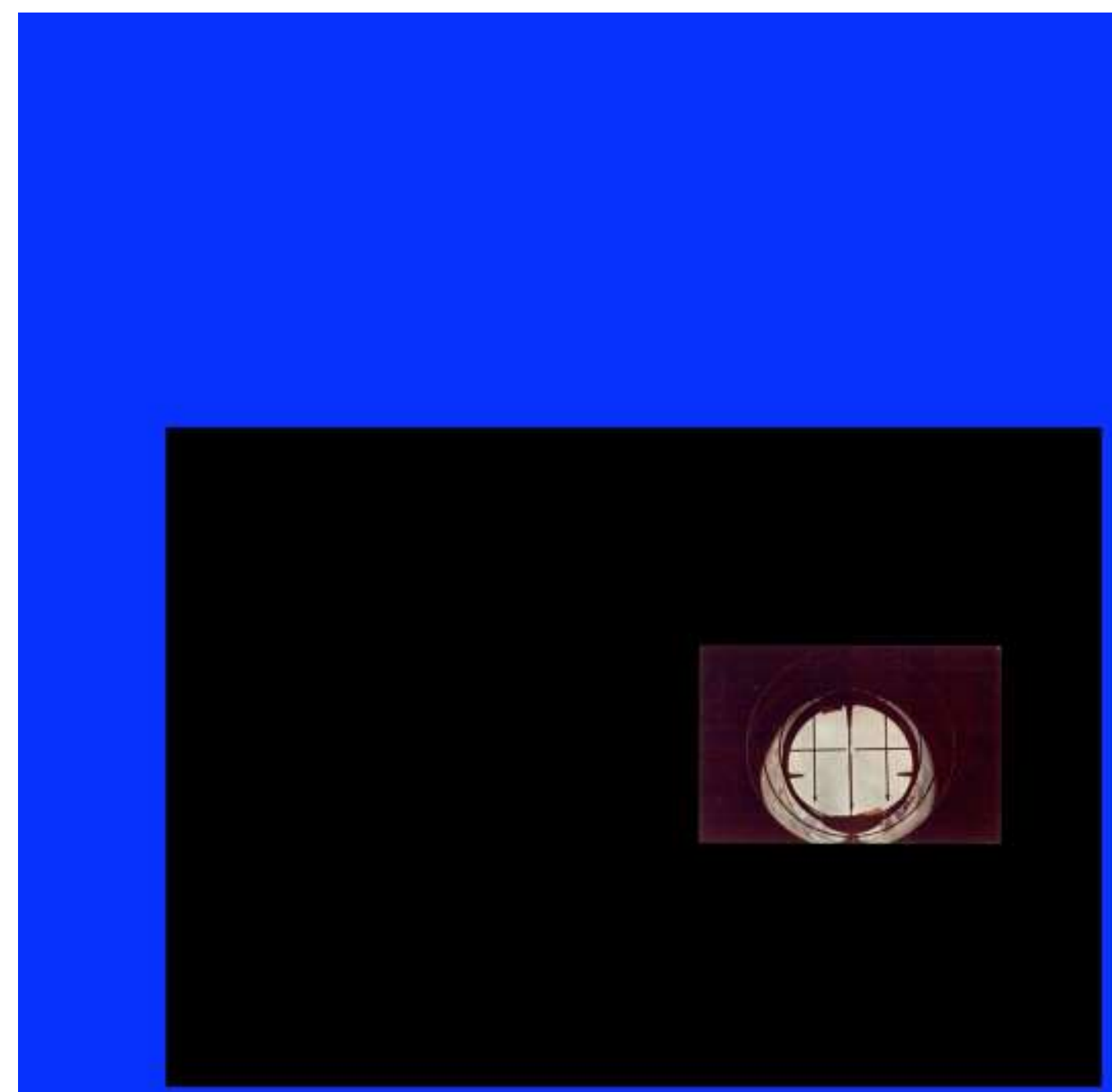




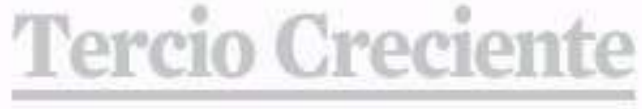

ISSN: 2340-9096

https://doi.org/10.17561/rtc.extra5.5799

娄
Revista de Estudios en Sociedad,

Artes y Gestión Cultural

Extraordinario V

Abril 2021

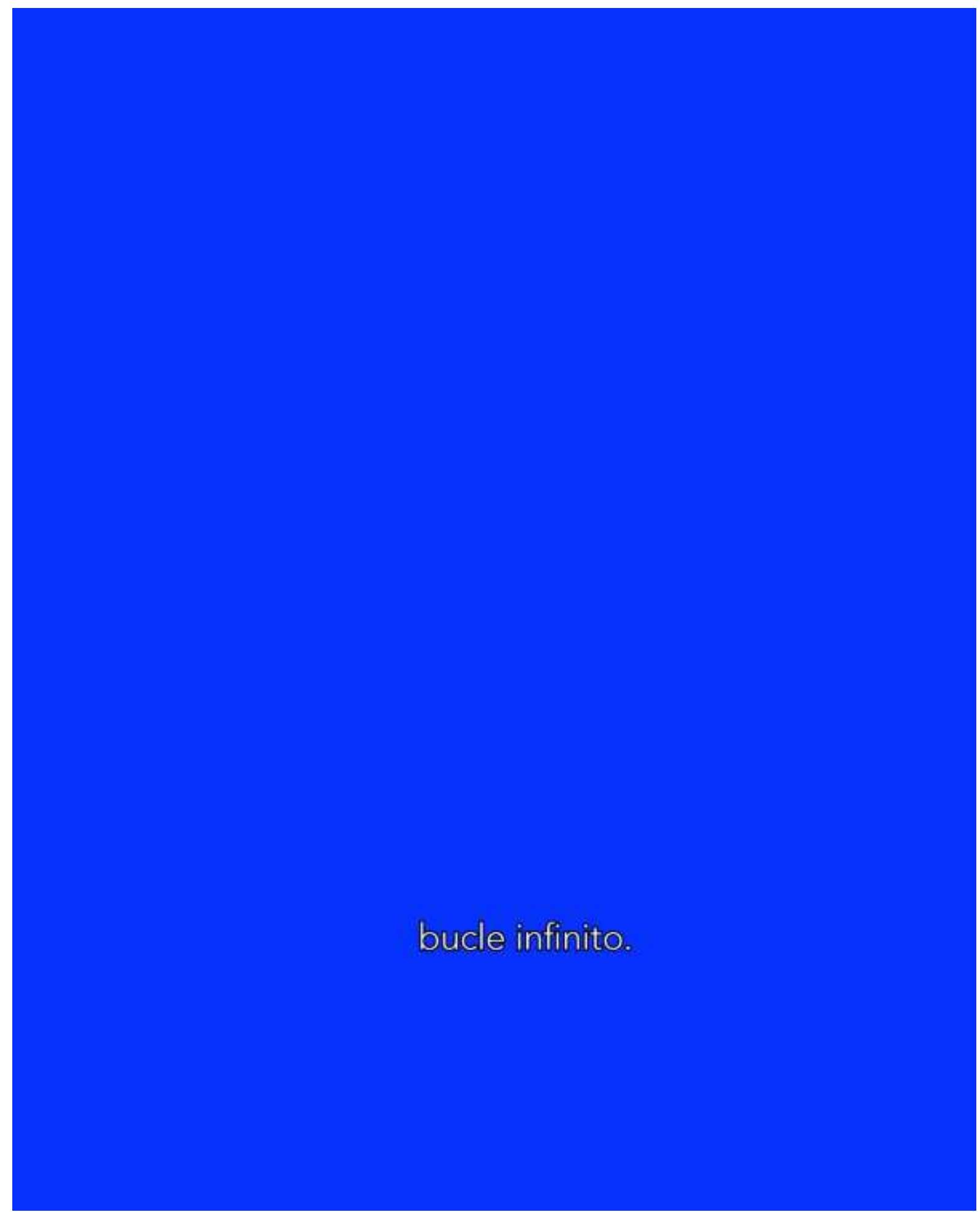


Revista de Estudios en Sociedad, Artes y Gestión Cultural
Monográfico

Extraordinario V

Abril 2021

ISSN: $2340-9096$

https://doi.org/10.17561/rtc.extra5.5799

(x)

\section{Referencias}

Todas las imágenes de este ensayo forman parte del proyecto Libres de espacio libre / en la cuerda floja de Edurne González Ibáñez, 2019-2020. 